\title{
Chemical kinetic model uncertainty minimization through laminar flame speed measurements
}

\author{
Okjoo Park $^{\mathrm{a}, 1, *}$, Peter S. Veloo ${ }^{\mathrm{b}}$, David A. Sheen ${ }^{\mathrm{c}}$, Yujie Tao ${ }^{\mathrm{d}}$, \\ Fokion N. Egolfopoulos ${ }^{\mathrm{a}}$, Hai Wang ${ }^{\mathrm{d}}$ \\ ${ }^{a}$ Department of Aerospace and Mechanical Engineering, \\ University of Southern California, Los Angeles, CA 90089-1453, USA \\ ${ }^{b}$ Exponent, Los Angeles, CA 90066, USA \\ ${ }^{c}$ Chemical Sciences Division, National Institute of Standards and Technology, Gaithersburg, MD \\ 20899, USA \\ ${ }^{d}$ Department of Mechanical Engineering, Stanford University, Stanford, CA 94305-3032, USA \\ Full length article submitted to Combustion and Flame \\ Running title: Uncertainty minimization through laminar flame speed measurements \\ *Corresponding Author \\ Okjoo Park \\ Energy Storage and Distributed Resources Division \\ Lawrence Berkeley National Laboratory \\ 1 Cyclotron Road \\ Berkeley, California 94720, USA
}

Phone: 510-486-6683

Email: okjoo.park@gmail.com

April 2, 2016

\footnotetext{
${ }^{1}$ Current address: Lawrence Berkeley National Laboratory, CA, 94720
} 


\title{
Chemical kinetic model uncertainty minimization through laminar flame speed measurements
}

\author{
Okjoo Park $^{\mathrm{a}, 1, *}$, Peter S. Veloo ${ }^{\mathrm{b}}$, David A. Sheen ${ }^{\mathrm{c}}$, Yujie Tao ${ }^{\mathrm{d}}$, \\ Fokion N. Egolfopoulos ${ }^{\mathrm{a}}$, Hai Wang ${ }^{\mathrm{d}}$ \\ ${ }^{a}$ Department of Aerospace and Mechanical Engineering, \\ University of Southern California, Los Angeles, CA 90089-1453, USA \\ ${ }^{b}$ Exponent, Los Angeles, CA 90066, USA \\ ${ }^{c}$ Chemical Sciences Division, National Institute of Standards and Technology, Gaithersburg, MD \\ 20899, USA \\ ${ }^{d}$ Department of Mechanical Engineering, Stanford University, Stanford, CA 94305-3032, USA
}

\begin{abstract}
Laminar flame speed measurements were carried for mixture of air with eight $\mathrm{C}_{3-4}$ hydrocarbons (propene, propane, 1,3-butadiene, 1-butene, 2-butene, iso-butene, $n$-butane, and iso-butane) at the room temperature and ambient pressure. Along with $\mathrm{C}_{1-2}$ hydrocarbon data reported in a recent study, the entire dataset was used to demonstrate how laminar flame speed data can be utilized to explore and minimize the uncertainties in a reaction model for foundation fuels. The USC Mech II kinetic model was chosen as a case study. The method of uncertainty minimization using polynomial chaos expansions (MUM-PCE) (D.A. Sheen and H. Wang, Combust. Flame 2011, 158, 2358-2374) was employed to constrain the model uncertainty for laminar flame speed predictions. Results demonstrate that a reaction model constrained only by the laminar flame speed values of methane/air flames notably reduces the uncertainty in the predictions of the laminar flame speeds of $\mathrm{C}_{3}$ and $\mathrm{C}_{4}$ alkanes, because the key chemical pathways of all of these flames are similar to each other. The uncertainty in model predictions for flames of unsaturated $\mathrm{C}_{3-4}$ hydrocarbons remain significant without considering fuel specific laminar flames speeds in the constraining target data set, because the secondary rate controlling reaction steps are different from those in the saturated alkanes. It is shown that the constraints provided by the laminar flame speeds of the foundation fuels could reduce notably the uncertainties in the predictions of laminar flame speeds of $\mathrm{C}_{4}$ alcohol/air mixtures. Furthermore, it is demonstrated that an accurate prediction of the laminar flame speed of a particular $\mathrm{C}_{4}$ alcohol/air mixture is better achieved through measurements for key molecular intermediates formed during the pyrolysis and oxidation of the parent fuel.
\end{abstract}

Keyword: Laminar flame speeds, uncertainty quantification, kinetics, chemical model development, alkanes, alkenes

\footnotetext{
${ }^{1}$ Current address: Lawrence Berkeley National Laboratory, CA, 94720
} 


\section{Introduction}

Reliable chemical kinetic models for the combustion of foundation fuels are a key component towards rational design of practical combustors. The hierarchical nature of combustion chemistry means that the high-temperature reactions of a basis set compounds, including $\mathrm{H}_{2}, \mathrm{CO}$, and $\mathrm{C}_{n} \mathrm{H}_{m}$, form the kinetic foundation for the combustion reactions of higher hydrocarbons. Here, $n$ is typically around four [1] although, depending on the fuel structure and composition, aromatic species such as benzene and toluene, may also belong to this set of species. This set of fuels will be referred to as the foundational fuels, and a corresponding reaction model is called foundational fuel chemistry model. During the combustion of large hydrocarbons, foundational fuel species are formed as intermediates; their oxidation is usually the rate controlling process.

Flame properties of $\mathrm{H}_{2}, \mathrm{CO}$, and $\mathrm{C}_{1-2}$ hydrocarbons have been intensively studied over the last several decades (e.g., [2-6]). Efforts that use laminar flame speeds, $S_{u}^{\circ}$, or other global combustion properties to test kinetic models have even a longer history (e.g., [7-14]). The chemistry of $\mathrm{C}_{3-4}$ unsaturated hydrocarbons has also garnered attention. These species are often the key intermediates in high-temperature oxidation of large hydrocarbons (e.g., $[15,16])$ and bio-derived alcohols (e.g., [17-19]). It has been demonstrated, for example, that uncertainties in the reaction kinetics of intermediates, such as $i$ so-butene $\left(i-\mathrm{C}_{4} \mathrm{H}_{8}\right)$ and propene $\left(\mathrm{C}_{3} \mathrm{H}_{6}\right)$ can impact model predictions of $i s o$-octane combustion properties $[15,16]$. In the oxidation of iso- and tertbutanol, $i-\mathrm{C}_{4} \mathrm{H}_{8}$ was found to be one of the key intermediates (e.g., [19, 20]); and our ability to predict the flame properties of these alcohols relies on the accuracy of chemistry specific to $i$ $\mathrm{C}_{4} \mathrm{H}_{8}$ and reactions of $\mathrm{H}_{2} / \mathrm{CO}$ species.

Reaction model development proceeds in two initial steps. A set of reactions and their rate parameters is compiled first. The model is then tested against a set of experimental measurements. For every rate parameter, there exists an associated uncertainty [21], which collectively manifests either as uncertainties in the model prediction of a combustion phenomenon or as quantitative experiment-model disagreements [22]. In practice, the as- 
compiled model is often tuned to bring predictions and measurements into agreement, and in a vast majority of instances the tuning is performed in an ad hoc manner. In most cases, the experimental datasets chosen for validation cover too small a thermodynamic condition space [23], and different modeling studies often use different experimental measurements that may or may not overlap each other. For this reason there still exist large discrepancies in predictions made by available reaction models even for the most basic combustion properties such as $S_{u}^{\circ}$ [24]. For large fuels, the matter is complicated by the fact that when experiment-model discrepancy arises, it is often difficult to assess the cause for such discrepancy owing to difficulties in isolating the uncertainties that can originate from the fuel specific kinetics and the foundation fuel chemistry. Here, fuel specific kinetics refers to pathway and rates of the parent fuel outside the foundational fuel chemistry set.

To effectively isolate the uncertainties in the fuel specific kinetics and foundation fuel chemistry, it is essential to first understand and minimize the contribution of kinetic uncertainties derived from the foundation model. Within this foundation fuel chemistry model the oxidation kinetics of unsaturated hydrocarbons have been studied to a far lesser degree than straight chain $n$-alkanes. The purpose of the present study is to supplement the earlier works [24, 25], as it presents a self-consistent set of $S_{u}^{\circ}$ data of 12 relevant $\mathrm{C}_{1-4}$ hydrocarbons. Specifically, measurements were made for $S_{u}^{\circ}$ of mixtures of eight hydrocarbons with air at atmospheric pressure. These are $\mathrm{C}_{3} \mathrm{H}_{6}$, propane $\left(\mathrm{C}_{3} \mathrm{H}_{8}\right)$, 1,3-butadiene $\left(1,3-\mathrm{C}_{4} \mathrm{H}_{6}\right)$, 1-butene $\left(1-\mathrm{C}_{4} \mathrm{H}_{8}\right)$, 2butene $\left(2-\mathrm{C}_{4} \mathrm{H}_{8}\right), i-\mathrm{C}_{4} \mathrm{H}_{8}, n$-butane $\left(n-\mathrm{C}_{4} \mathrm{H}_{10}\right)$, and iso-butane $\left(i-\mathrm{C}_{4} \mathrm{H}_{10}\right)$. Comparisons were made against archival data [2-4, 24-32]. Moreover, we demonstrate how this set of experiments can be used to constrain foundation fuel chemistry models, using USC Mech II [33] as the test case of this demonstration.

The Method of Uncertainty Minimization using Polynomial Chaos Expansions (MUM-PCE) $[23,34]$ was applied to constrain the aforementioned kinetic model with the intent to better understand the role of $S_{u}^{\circ}$ measurements in model uncertainty constraining. Utilizing the experimental $S_{u}^{\circ}$ datasets, several questions critical to the utility of the $S_{u}^{\circ}$ data were explored. 


\section{Experimental Method}

All $S_{u}^{\circ}$ measurements were carried out in the counterflow configuration at atmospheric pressure, $p=1 \mathrm{~atm}$ and at an unburned reactant temperature, $T_{\mathrm{u}}=298 \mathrm{~K}$. The burner nozzle diameters and nozzle-to-nozzle separation distance were both $1.4 \mathrm{~cm}$. $S_{u}^{\circ}$ 's were determined using the twin-flame technique $[35,36]$ over a wide range of equivalence ratios, $\phi$. Flow velocities were measured using particle image velocimetry. The flow was seeded with droplets of silicone oil by a high efficiency nebulizer. The minimum axial flow velocity upstream of the flame was defined as the reference flame speed, $S_{\mathrm{u}, \text { ref }}$, and the maximum absolute value of the velocity gradient upstream of the flame is defined as the strain rate, $K$. $S_{u}^{\circ}$ 's were determined through nonlinear extrapolations of $S_{\mathrm{u}, \text { ref }}$ to $K=0$ using a computationally-assisted approach [37]. Samples of the extrapolation method are presented in Fig. S1 of the Supplementary Material (SPM). 


\section{Reaction Models}

Primary analyses were carried out using USC Mech II [33]. The reaction model consists of 111 species and 784 elementary reactions, and describes the high temperature oxidation kinetics of $\mathrm{H}_{2} / \mathrm{CO}$ and $\mathrm{C}_{1}-\mathrm{C}_{4}$ hydrocarbons. The model has been tested against shock-tube ignition delay times, $S_{u}^{\circ}$, s, and speciation measurements in flow reactors, shock tubes, and burner stabilized flames for a wide range of small hydrocarbon fuels, including benzene and toluene. Although a systematic optimization was made for the $\mathrm{H}_{2} / \mathrm{CO}$ kinetic subset [39], USC Mech II as a whole is not tuned to fit specific sets of data. For the current optimization study, the rate parameters of the $\mathrm{H}_{2} / \mathrm{CO}$ subset were restored to their nominal values listed in Ref. [39]. Additionally, the rate parameter for $\mathrm{OH}+\mathrm{HO}_{2} \leftrightarrow \mathrm{H}_{2} \mathrm{O}+\mathrm{O}_{2}$ was revised using the expression of Baulch et al. [40], which was shown to represent more accurately the experimental studies [41, 42]. For the reaction $\mathrm{H}+\mathrm{O}_{2}+\mathrm{M} \leftrightarrow \mathrm{HO}_{2}+\mathrm{M}$, the collision efficiency of $\mathrm{H}_{2} \mathrm{O}$ was taken to be an active, optimization parameter.

The reaction model just described is referred to as the unconstrained or prior model. Uncertainty factors for the Arrhenius pre-factors in USC Mech II are provided in the supplementary material of Ref. [34]. These factors were taken either in consultation with 
literature (e.g., [40,43]) or through evaluation [23, 34]. The coupled uncertainty in the activation energy and the pressure fall-off parameters was not considered in the present work.

Several representative literature models (summarized in Table 1) were chosen to demonstrate the degree of spread in $S_{u}^{\circ}$ predictions by literature models. In all cases, these are some of the well-documented and frequently used reaction models. Unless otherwise indicated, we shall use the abbreviated names for these models in discussion thereafter.

\section{Computational Details}

MUM-PCE was employed to evaluate the prior model against experimental datasets of $S_{u}^{\circ}$ 's of mixtures of $\mathrm{C}_{1}-\mathrm{C}_{4}$ hydrocarbons with air. The model was represented by a multivariate polynomial response surface at each selected experimental condition. The reaction pre-factors were ranked in order of their uncertainty-weighted sensitivity coefficients for each experimental target. $S_{u}^{\circ}$ 's were computed using the PREMIX code [50] along with the Sandia CHEMKIN [51] and the transport subroutine libraries [52]. The transport parameters were based on an updated library with changes made to the binary diffusion coefficients involving $\mathrm{H}$ and $\mathrm{H}_{2}[53,54]$. The computations used windward differencing and multicomponent transport formulations with at least 600 adaptive grid points to cover a computational domain of $15 \mathrm{~cm}$.

Prediction uncertainty was quantified by the stochastic spectral expansion method [55-57] and the model was constrained by experimental data. It should be noted that the model posterior uncertainty space strongly depends on the uncertainties of the experimental measurements [23]. The posterior model uncertainties were quantified by MUM-PCE, which has been discussed extensively in previous work [22, 23, 34]. Briefly, each rate coefficient is normalized as a factorial variable [21],

$$
x_{i}=\frac{\ln \left(k_{i} / k_{i, 0}\right)}{\ln f_{i}} \text {, }
$$


where $k_{i}$ is the rate coefficient of the $i^{\text {th }}$ reaction, $k_{i, 0}$ is its nominal value, and $f_{i}$ is its span or the uncertainty factor of the rate coefficient. Thus $x_{i}=0$ represents the nominal rate value, and $x_{i}=-$ 1 and +1 are the lower $k_{i}=k_{i, 0} / f_{i}$ and upper $k_{i}=k_{i, 0} \times f_{i}$ bounds of uncertainty in $k_{i, 0}$, respectively. In this formulation, simple multipliers for Arrhenius pre-factors were treated, although temperature and pressure dependence in the rate expression may be important for consideration. In the current work, these dependencies were not considered because the $S_{u}^{\circ}$ targets do not give enough resolution to warrant such an exercise.

In MUM-PCE, the kinetic parameter and its associated uncertainty is expressed as a polynomial expansion of $m$ basis random variables,

$$
x_{i}=x_{i}^{(0)}+\sum_{j=1}^{m} \alpha_{i j} \xi_{j}
$$

where $\boldsymbol{\alpha}_{i}$ is the vector of expansion coefficient, $\xi_{j}$ is the $i^{\text {th }}$ basis variable, $m$ is the number of basis variables considered in the expansion, and $\mathbf{x}^{(0)}$ is the vector of normalized rate coefficients, which are zero for a prior model and can be non-zero upon model optimization.

The solution mapping technique was used to map the solutions of differential equations in the form of an algebraic expansion or a response surface [21]. MUM-PCE assumes that the dependency of flame speed prediction on the factorial variables, $s_{u}^{\circ}(\mathbf{x})$, can be approximated by a second-order polynomial [23]:

$$
S_{u}^{\circ}(\mathbf{x})=S_{u, 0}^{\circ}+\sum_{i=1}^{N_{r}} a_{i} x_{i}+\sum_{i=1}^{N_{r}} \sum_{j \geq i}^{N_{r}} b_{i j} x_{i} x_{j}
$$

where $S_{u, 0}^{\circ}$ is the nominal flame speed value and $N_{r}$ represents the number of active parameters. The coefficients $a_{i}$ and $b_{i j}$ were determined by a regression test against computational experiments from the Sensitivity-Analysis-Based (SAB) method [58]. The accuracy of the response surface is verified by comparing $S_{u}^{\circ}$ calculated using the PREMIX flame code against the calculations made using the polynomial predictions of $S_{u}^{\circ}$. The $45^{\circ}$ diagonal line plot shown in Fig. S2 of SPM shows a sample of such response surfaces and demonstrates that the accuracy of the response surface is excellent. The mean error between the response surface prediction and 
the directly computed $S_{u}^{\circ}$ is $<0.5 \%$ within the hyper-dimensional space defined by the span values of the respective rate coefficients. The maximum error is well below the uncertainty of the experimental data, as will be discussed later.

Combining solution mapping and spectral expansion methods for uncertainty propagation, Eq. (4) provides the prediction of $S_{u}^{\circ}$ of the $r^{\text {th }}$ experiment with its associated uncertainty contributed by each rate coefficient uncertainty in the model,

$$
S_{u, r}^{\circ}(\xi)=S_{u, r}^{\circ}\left(\mathbf{x}^{(0)}\right)+\sum_{i=1}^{m} \hat{a}_{r, i} \xi_{i}+\sum_{i=1}^{m} \sum_{j=i}^{m} \hat{\beta}_{r, i j} \xi_{i} \xi_{j} .
$$

The model prediction uncertainty $\sigma_{r}$ is determined from the coefficients in Eq. (4) as:

$$
\begin{aligned}
\sigma_{r}^{2}(x) & =E\left[\left\{S_{u, r}^{\circ}(\xi)\right\}^{2}\right]-E^{2}\left[S_{u, r}^{\circ}(\xi)\right] \\
& =\sum_{i=1}^{m} \hat{\alpha}_{r, i}^{2}+2 \sum_{i=1}^{m} \hat{\beta}_{r, i i}^{2}+\sum_{i=1}^{m-1} \sum_{j=i+1}^{m} \hat{\beta}_{r, i j}^{2} .
\end{aligned}
$$

Due to optimization against the experimental target set, the factorial variables are updated to the values best able to fit the given experimental measurements, denoted as $\mathbf{x}^{*}$. The best-fit values will have an expansion in terms of the basis random variables:

$$
x_{i}^{*}=x_{i}^{(0)^{*}}+\sum_{j=1}^{m} \alpha_{i j}^{*} \xi_{j}
$$

The best-fit factorial variables $\mathbf{x}^{(0) *}$ are found by solving the least-squares optimization problem,

$$
\Phi\left(\mathbf{x}^{(0)^{*}}\right)=\min _{\mathbf{x}^{(0)}}\left\{\sum_{r=1}^{N_{e}}\left[\frac{S_{u, r}^{\circ}\left(\mathbf{x}^{(0)}\right)-S_{u, r}^{\circ, \mathrm{obs}}}{\sigma_{r}^{\mathrm{obs}}}\right]^{2}+\sum_{n=1}^{N_{r}}\left[\frac{x_{n}}{\sigma_{n}}\right]^{2}\right\} .
$$

In the above equation, $S_{u, r}^{\circ, \text { obs }}$ is the $r^{\text {th }}$ flame speed target and $\sigma_{r}^{o b s}$ its uncertainty, and $N_{e}$ is the total number of experimental measurements. $\mathbf{x}^{(0)^{*}}$ is then an optimal set of rate coefficients by minimizing the least-squares difference between the model predictions and the experimental measurements, weighted by experimental uncertainty. The second term of Eq. (7) comes from treating each rate parameter value as an experiment in its own right, with uncertainty $\sigma_{n}$ equal to 
In the above equation, $\mathbf{J}_{r}^{*}$ is the gradient of the $r^{\text {th }}$ model response with respect to the factorial variables, evaluated at $\mathbf{x}^{(0)^{*}}$ and $\mathbf{I}$ is the identity matrix, following which $\boldsymbol{\alpha}^{*}$ is calculated from the Cholesky factorization of $\Sigma^{*}$.

It is worthwhile to have a brief discussion about the degree of freedom of the system. Because the $S_{u}^{\circ}$ target data are not entirely independent of each other and considering the large number of rate parameters that may impact the flame speed prediction, the mathematical system remains under-defined. This is unfortunately a general feature of reaction model development. It is precisely for this reason that the above covariance matrix technique was introduced: although it is impossible to constrain the model parameters to a unique set, the joint probability distribution function provides coupled ranges of uncertainty of the rate parameters within which the target data can be reconciled.

Consideration will now be given to the circumstance whereby a constrained $S_{u}^{\circ}$ prediction, $S_{u, r}^{\circ}\left(\mathbf{x}^{(0)^{*}}\right)$, do not agree with the corresponding experimental observation, $S_{u, r}^{\circ, \text { bs }}$. The disagreement could be caused by a number of factors including, but not limited to, understatement of experimental uncertainty, under-estimation of rate parameter uncertainty, and missing reaction pathways within the model. Towards addressing these issues, a data-consistency analysis algorithm [23] was proposed. Constraining the uncertainty of a kinetic model is a twostage process. Firstly, the model is constrained by minimizing the least-squares difference between the model prediction and experimental measurements, weighted by $\sigma_{r}^{o b s}$. MUM-PCE will then check for inconsistencies in the experimental target dataset by calculating the contribution of the $r^{\text {th }}$ experiment to the objective function, $F_{r}$ [23]: 


$$
F_{r}=\frac{S_{u, r}^{\circ, \mathrm{obs}}-S_{u}^{\circ}\left(x_{0}^{*}\right)}{2 \sigma_{r}^{\mathrm{obs}}} .
$$

If, the $r^{\text {th }}$ experiment is deemed inconsistent with the initially constrained model if the model prediction falls outside the $r^{\text {th }}$ experimental target's uncertainty bounds. The effect of a particular target on the constrained model is measured by the normalized scalar product $S_{\mathrm{r}}$ between the response surface gradient $\nabla S_{u, r}^{\circ}\left(x^{*}\right)$ and the constrained factorial vector or the change in the response caused by model constraint [23],

$$
S_{r}=\frac{\left[\nabla S_{u, r}^{\circ}\left(x^{*}\right)\right] \cdot\left[x^{*}\right]}{\left\|\nabla S_{u, r}^{\circ}\left(x^{*}\right)\right\| \cdot\left\|x^{*}\right\|} .
$$

The target with the greatest effect on the posterior model will have the largest value of $S_{r}$.

If only one target satisfies the criteria, $\left|F_{r}\right|>1$, it will be removed from the optimization data target set and the model is then re-constrained. However, when multiple targets satisfy $\left|F_{r}\right|>1$, MUM-PCE first calculates the weighted scalar product $W_{\mathrm{r} \text { : }}$

$$
W_{r}=S_{r} F_{r}
$$

The single target that has the greatest $\left|W_{r}\right|$ is removed and the model is then re-constrained. This procedure was repeated until an $\mathbf{x}^{*}$ is calculated such that all $F_{r}$ are smaller than unity. These tests are referred to as $F$ and $W$ tests, respectively. If the standard deviation of the target experiment $\left(\sigma_{r}^{o b s}\right)$ was small, it will tend to have a greater impact on the posterior model so it would have a large contribution to the optimized value, and hence have larger $S_{r}$ value.

\section{Results and Discussion}

\subsection{Experimental data}

Figure 1 summarizes the experimental $S_{u}^{\circ}$ 's for mixtures of $\mathrm{C}_{3-4}$ hydrocarbons with air at $T_{\mathrm{u}}=298 \mathrm{~K}$ and $p=1 \mathrm{~atm}$. The variations of $S_{u}^{\circ}$ with respect to $\phi$ and the fuel structure are well 
within our understanding: alkenes have higher $S_{u}^{\circ}$ 's than comparable alkanes largely because of differences in the adiabatic flame temperature; branched chain alkane and alkenes have lower $S_{u}^{\circ}$ 's than comparable straight-chain compounds, because of fuel structure influence on the formation of intermediates and their resulting radical production and destruction.

Measurements made in the current work and from prior studies of the USC group [24, 25] all tend to result in somewhat lower $S_{u}^{\circ}$ values than other studies especially under fuel rich conditions. For example, values reported for $\mathrm{CH}_{4}$ /air flames by Bosschaart and de Goey [27] are larger than those of the present authors' values by about $6 \mathrm{~cm} / \mathrm{s}$ at $\phi \leq 1.3$. The discrepancy just discussed is a cause for concern, and for this reason experimental $S_{u}^{\circ}$ values for all $\mathrm{C}_{1}-\mathrm{C}_{4}$ hydrocarbons considered here are compared in Figs. S3-S5 of SPM. The data are plotted as a function of the equivalence ratio, and following Law et al. [59], also the normalized equivalence ratio $\bar{\phi}=\phi /(1+\phi)$. The data shown were determined using a number of techniques, including counterflow flames [2, 3, 24, 25, 31], stagnation flames [26], spherically expanding flames [4, 28-30, 32], and the heat flux [27] methods. With the exception of acetylene for which the measurements were made in $\mathrm{N}_{2}$-diluted air, all others are fuel/air mixtures with the unburned gas temperature $T_{\mathrm{u}}=298 \mathrm{~K}$ and pressure $p=1$ atm and over a range of $\phi$ 's.

In general, the reproducibility of $S_{u}^{\circ}$ values is reported to be $\pm 2 \mathrm{~cm} / \mathrm{s}$ or better within each laboratory. Yet from laboratory to laboratory the data scatter is larger. In almost all cases, the nominal $S_{u}^{\circ}$ values and their uncertainties, when provided, do not overlap; and the data discrepancy remains too large to draw a consensus about the $S_{u}^{\circ}$ value for any fuel to within $\pm 2 \mathrm{~cm} / \mathrm{s}$. The left panel of Fig. 2 shows the results of rational function analysis [59] of the data uncertainty for $\mathrm{C}_{3} \mathrm{H}_{6}$ /air and $1-\mathrm{C}_{4} \mathrm{H}_{8}$ /air mixtures. A similar result is shown for $\mathrm{CH}_{4} /$ air mixtures in Fig. 3, and additional results are presented in Figs. S3-S5 of SPM for fuels where statistically significant numbers of measurements are available. The width of the $2 \sigma$-uncertainty band of the data varies typically from roughly $\pm 5 \mathrm{~cm} / \mathrm{s}$ to $\pm 7.5 \mathrm{~cm} / \mathrm{s}$ for all fuels analyzed. These uncertainty band sizes are substantially larger than the uncertainty reported in individual studies. Clearly, the 
uncertainty values as reported in the individual studies should be considered as the reproducibility of the data for a given method in a given facility.

At least some of the data scatter is the result of systematic error that is known to have occurred in data interpretation. For example, the $S_{u}^{\circ}$ values reported by Davis and Law [3] and Kumar et al. [31] are impacted by the assumption of linear dependency of the reference velocity with respect to flow stretch. The assumption produces systematically larger $S_{u}^{\circ}$ values for the fuels considered. For $1-\mathrm{C}_{4} \mathrm{H}_{8}$ and maybe some other fuels, the method of extrapolation is perhaps insufficient to explain the discrepancy of the $S_{u}^{\circ}$ 's values between Davis and Law [3] and those determined here, as discussed in section S1 of SPM.

How to treat the interlaboratory uncertainty is an as-yet unresolved question [22], as discussed in a recent review. There are three schools of thought on this issue. In the MUM-PCE algorithm used here and in related works [22, 23], a model is generated that agrees with as many measurements as possible, each of which has its own uncertainty. In the Bayesian algorithm used by Raman and coworkers [60], every measurement has the same uncertainty which is solved for as part of the optimization problem. Finally, Turanyi and coworkers [61] present a hybrid approach, wherein there is a component of the uncertainty for each measurement reported by the investigators and a component coming from the scatter in the measurements that is evaluated as part of the optimization problem.

Each method has its advantages and disadvantages, which can be seen most clearly in the case of a single spurious measurement with an unreasonably small uncertainty that does not agree with the other measurements of its type. In the case of MUM-PCE, this experiment might end up being labeled as inconsistent and as such removed, or it might end up overwhelming all the other measurements and generating a model that is consistent with neither the actual physics nor the actual precision of that physics; that is, the physics will be wrong and it will be overconfidently wrong. In methods of [60] or [61], this single measurement would instead introduce a large uncertainty into the posterior model. Turányi and coworkers [62] have also implemented an approach to handling inconsistent data whereby data not reproduced within 4 


\subsection{Comparisons among models and experimental data}

Prediction uncertainties of USC Mech II remain large. The right panel of Fig. 2 depicts the probability density functions and the $2 \sigma$ uncertainty bands of the model, calculated for $\mathrm{C}_{3} \mathrm{H}_{6}$ and $1-\mathrm{C}_{4} \mathrm{H}_{8}$ flames using eq (4). In these figures, the dashed lines correspond to predictions at $\pm 2 \sigma$ uncertainty or $95 \%$ confidence interval. The intensity of the grey level represents the normalized probability density function. For comparison, the $2 \sigma$ uncertainty values computed for $S_{u}^{\circ}$ 's of $\mathrm{C}_{3} \mathrm{H}_{6}$ flames are \pm 7.5 and $\pm 5 \mathrm{~cm} / \mathrm{s}$ for $\phi=1.0$ and $\phi=1.2$, respectively. These values are \pm 10 and $\pm 8.5 \mathrm{~cm} / \mathrm{s}$ for $1-\mathrm{C}_{4} \mathrm{H}_{8}$ at $\phi=1.0$ and $\phi=1.4$, respectively. The somewhat larger uncertainty values of $1-\mathrm{C}_{4} \mathrm{H}_{8}$ are the result of a larger number of fuel-specific reactions that impact $S_{u}^{\circ}$ of $1-\mathrm{C}_{4} \mathrm{H}_{8}$ flames. Yet, the $S_{u}^{\circ}$ model prediction uncertainty of $\mathrm{C}_{3} \mathrm{H}_{6}$ and $1-\mathrm{C}_{4} \mathrm{H}_{8}$ is not substantially larger than that of $\mathrm{CH}_{4}$. As shown in the right panel of Fig. 3, $\mathrm{CH}_{4}$ has a prediction uncertainty of $\pm 7 \mathrm{~cm} / \mathrm{s}$ at $\phi=1.0$, and $\pm 8 \mathrm{~cm} / \mathrm{s}$ at $\phi=1.3$, similar to the values computed by Zádor et al. [63]. 
This comparison is consistent with our understanding that $S_{u}^{\circ}$ is influenced by a set of common reactions that govern the radical processes in flames regardless which hydrocarbon fuel it is.

While we have a poor convergence of the experimental data, there is some convergence in the predictions by the reaction models. As shown in Fig. 2, the prediction of the original Galway model (model g) lies outside the $2 \sigma$ uncertainty bands of USC Mech II for some fuel-rich $\mathrm{C}_{3} \mathrm{H}_{6}$ and $1-\mathrm{C}_{4} \mathrm{H}_{8}$ flames, suggesting fundamental kinetic differences between the models. The more recent models, Aramco Mech 1.3 (model a-1) and Aramco Mech- $\mathrm{C}_{3} \mathrm{H}_{6}$ (model a-2), on the other hand, show notable improvements over the original Galway model. More importantly, if the rate parameter uncertainties assigned in USC Mech II are realistic, the predictions by USC Mech II and the two versions of the Aramco models all fall within the expected uncertainties of the rate parameters for at least $\mathrm{C}_{3} \mathrm{H}_{6}$.

For $\mathrm{CH}_{4}$ flames, discrepancies are still significant among model predictions, as shown in Fig. 3, despite the fact that the Galway, Aramco, and San Diego models all predict $S_{u}^{\circ}$ values well within the $2 \sigma$-uncertainty band of USC Mech II. Thus, fundamental differences among these reaction models, if any, are not manifested as far as $S_{u}^{\circ}$ prediction here. Rather, the discrepancies in model prediction are the most likely the result of choices of rate parameters. 


\subsection{Model optimization and uncertainty minimization}

As we discussed earlier, it is not our purpose to explore the sources of discrepancy among $S_{u}^{\circ}$ data, nor is it our intention to explore differences in the kinetic assumptions of the different models and their resulting impacts on $S_{u}^{\circ}$ prediction. Our purpose is to explore the question of, given the current state of knowledge in the $S_{u}^{\circ}$ 's of almost every relevant $\mathrm{C}_{1-4}$ hydrocarbon compounds, what we can learn from the data as far as model accuracy is concerned. In particular, how small can the prediction uncertainty of the model become for $S_{u}^{\circ}$ predictions, based on experimental knowledge? For this purpose, multiple sets of experimental data of $\mathrm{C}_{1-4} S_{u}^{\circ}$ 's were tested as optimization targets. Sources of target data and the corresponding labels for the posterior models are listed in Table 2. Table 3 lists the target values and their $2 \sigma$ uncertainty values. For those data values where an uncertainty estimate is reported, that estimate was used as is. Otherwise, the uncertainty was assumed to be $\pm 2 \mathrm{~cm} / \mathrm{s}$. Excluding the data of Davis and Law [3] and Kumar et al. [31] (see Section 5.1), the spread in experimental $S_{u}^{\circ}$ values is generally smaller than the prediction uncertainty of the prior model. Therefore a model jointly constrained by all relevant $\mathrm{C}_{1-4} S_{u}^{\circ}$ targets is expected to yield useful information about the impact of the current $S_{u}^{\circ}$ database on reaction model development.

To test the impact of the data scatter on model uncertainty minimization, three computational tests were made with increasingly larger target sets. First, only experimental data sets of $[24,25]$ and from the present work were considered as the optimization targets and the corresponding optimized model (posterior model) is referred to as OM I. The OM II and OM III target sets include those of OM I plus literature data values [3, 4, 26, 27, 31]. While the OM III set includes data considered, OM II considers all but those of Ref. [3, 31].

Active rate parameters were chosen for the optimization by considering jointly the sensitivity and uncertainty of a rate constant. For this purpose, an impact factor $u$ is introduced here:

$$
u=2\left(\frac{\partial \ln S_{u}^{\circ}}{\partial \ln A}\right) \ln f
$$


where $\partial \ln S_{u}^{\circ} / \partial \ln A$ is the logarithmic sensitivity coefficient. Figure 4 depicts the ranked impact factor $u$ and the corresponding sensitivity coefficient for $\mathrm{CH}_{4}$ and $1-\mathrm{C}_{4} \mathrm{H}_{8}$ as examples. Similar results can be seen for all other hydrocarbons in Figs. S6-S17 of SPM. As can be seen in these figures, reaction processes that impact flame propagation are typically those of $\mathrm{H}, \mathrm{CO}, \mathrm{HCO}$ and small HC species, yet owing to their larger uncertainty factors, the rate coefficients of some fuel specific reactions can impact the $S_{u}^{\circ}$ prediction notably. For example, the prediction of the $S_{u}^{\circ}$ of $1-\mathrm{C}_{4} \mathrm{H}_{8}$ is influenced by the uncertainty of the rate coefficient of reaction $\left(f_{\mathrm{R} 556} \sim 5\right)$

$$
1-\mathrm{C}_{4} \mathrm{H}_{8}+\mathrm{H} \rightarrow \mathrm{C}_{3} \mathrm{H}_{6}+\mathrm{CH}_{3} \text {. }
$$

despite the fact that the sensitivity coefficient of reaction R556 is substantially smaller than that of the key chain branching reaction $\mathrm{R} 1\left(f_{\mathrm{R} 1}=1.2\right)$

$$
\mathrm{H}+\mathrm{O}_{2} \rightarrow \mathrm{O}+\mathrm{OH} .
$$

Reaction (R1) has a large $u$ factor for nearly all fuels even though its uncertainty is about only $20 \%$. Other high-impact factor reactions that are common to all fuels include

$$
\begin{aligned}
& \mathrm{HCO}+\mathrm{H} \leftrightarrow \mathrm{CO}+\mathrm{H}_{2}\left(f_{\mathrm{R} 38}=3\right) \\
& \mathrm{HCO}+\mathrm{M} \leftrightarrow \mathrm{CO}+\mathrm{H}+\mathrm{M}\left(f_{\mathrm{R} 43}=2\right)
\end{aligned}
$$

and

$$
\mathrm{CH}_{3}+\mathrm{OH} \rightarrow \mathrm{CH}_{2}(\mathrm{~s})+\mathrm{H}_{2} \mathrm{O}\left(f_{\mathrm{R} 95}=5\right) \text {. }
$$

MUM-PCE results for the 12 fuels are shown in Figs. 5 through 10, in which we compare the probability density functions and $2 \sigma$ uncertainties of $S_{u}^{\circ}$ predicted using the prior model and the three optimized models. Several immediate observations can be made: (1) the MUM-PCE analysis reduces the prediction uncertainties of the reaction model notably when compared to those of the prior model; (2) with the exception of $1-\mathrm{C}_{4} \mathrm{H}_{8}$ and $2-\mathrm{C}_{4} \mathrm{H}_{8}$ (Fig. 9), USC Mech II is able to reconcile all data sets taken from $\operatorname{Ref}[24,25]$ and the present work, as seen in the OM I plots; (3) the effect of adding literature data beyond those of Ref [24, 25] is a somewhat increased $S_{u}^{\circ}$ value (as predicted by OM II and OM III compared to OM I); (4) the uncertainty band size decreases somewhat from OM I to OM II, suggesting the data beyond those from Ref $[24,25]$ and the present work help to constrain the model uncertainty to an extent. The fact that 
USC Mech II exhibits difficulties reconciling with the 1- $\mathrm{C}_{4} \mathrm{H}_{8}$ and $2-\mathrm{C}_{4} \mathrm{H}_{8} S_{u}^{\circ}$ data suggests that the reaction model may have missing reaction pathways relevant to their oxidation. Indeed the chemistry specific to $\mathrm{C}_{4} \mathrm{H}_{8}$ oxidation is known to be rather weak in USC Mech II. The elementary reaction kinetics of the $\mathrm{C}_{4} \mathrm{H}_{10}$ isomers are not as well understood as other fuels.

Most of the optimized rate parameters of $\mathrm{H}_{2} / \mathrm{CO} / \mathrm{HCO}$ reactions are centered around their nominal values, as shown in Table 4, in which the ratios of optimized-to-nominal rate coefficients of selected reactions are compared between OM I and OM II. The results show that the inclusion of additional targets from OM I to OM II did not lead to significant changes in individual, active rate parameters. Except for R95, the difference between OM I and OM II is rather small. The large change in the rate coefficient of R95 from OM I to OM II indicates that the current $S_{u}^{\circ}$ dataset yields little insight into $k_{95}$. Suffice it to note that many of the rate parameters in USC Mech II are outdated. Jasper et al. [65] carried out a careful analysis of $k_{95}$ as a part of study of the $\mathrm{CH}_{3}+\mathrm{OH}$ and methanol decomposition. At 1 atm pressure, they calculated $k_{95}$ to be around $4 \times 10^{12} \mathrm{~cm}^{3} / \mathrm{mol}-\mathrm{s}$ from 1500 to $2000 \mathrm{~K}$. The nominal value of $k_{95}$ in USC Mech II is $2.5 \times 10^{13} \mathrm{~cm}^{3} / \mathrm{mol}-\mathrm{s}$. Thus, the ratio values of Table 4 gives $k_{95}=3.8 \times 10^{13}$ and $1.2 \times 10^{13} \mathrm{~cm}^{3} / \mathrm{mol}-\mathrm{s}$ for OM I and II, respectively. Clearly, the OM I value diverges from the theoretical result of [65], while OM II yields the $k_{95}$ value closer to the theoretical result. Interestingly, the $k_{95}$ value optimized in OM II is quite close to Baulch's compilation [43], which gives $k_{95}$ to be $1.2 \times 10^{13} \mathrm{~cm}^{3} / \mathrm{mol}-\mathrm{s}$ at $1500 \mathrm{~K}$, decreasing to $9.3 \times 10^{12} \mathrm{~cm}^{3} / \mathrm{mol}$-s at $2000 \mathrm{~K}$.

The covariance matrix, $\Sigma$, indicates how the rate coefficients are constrained by experimental targets (see, Fig. S18 of SPM). The diagonal elements of $\Sigma$ are relatively large, indicating that the uncertainty of any single rate coefficient is not effectively constrained by $S_{u}^{\circ}$ measurements. Instead, as indicated by the off-diagonal elements of $\Sigma$, the constraint on the model uncertainty comes mostly in the form of interparameter coupling. The covariance matrix is relatively sparse, but there are several groups of reactions whose rate coefficients are prominently coupled. For instance, the uncertainty in $k_{95}$ is constrained relatively quite tightly, but $k_{95}$ is also strongly coupled to the rate coefficient of reaction R99: 
Interestingly, OM II yields an optimized $k_{99}$ to be $0.7 \times 1.34 \times 10^{13}=9.4 \times 10^{12} \mathrm{~cm}^{3} / \mathrm{mol}$-s, which is in better agreement with the more recent measurement of Hong et al. [66], $6.8 \times 10^{12} \mathrm{~cm}^{3} / \mathrm{mol}-\mathrm{s}$ with an uncertainty factor of 1.4. Additionally, OM II also gives a more reasonable R108 than OM I. Nonetheless, the coupling just discussed underscores the limitation of MUM-PCE, given the currently available data. The MUM-PCE method can be used to calculate the uncertainty of a simulation result and this can be compared directly with the corresponding experimental uncertainty. The results obtained from this method also indicated that the rate parameters are highly correlated and therefore assignation of an individual uncertainty limit to each parameter is not possible, such uncertainty limits have no physical meaning. However, the correlation matrix of the rate parameters can be used to characterize the joint uncertainty of the rate parameters, which is the only meaningful uncertainty measure for the rate parameters [23].

\subsection{Data consistency}

During the optimization process, a target may be removed either because multiple measurements for a particular experimental condition do not agree with each other or the experimental measurement cannot be reconciled with the other targets within the uncertainty bounds of the prior model. A comprehensive tabulation of the included and excluded datasets as a result of the F/W test is provided in Table S2 of SMP. For the case of OM I, none of the target experimental data was removed as optimization targets. Therefore, it can be concluded that, the OM I dataset forms a self-consistent target set within the framework of USC Mech II. The rejection of a target during optimization does not imply that the particular measurement was incorrect. It merely suggests that the data may need further evaluation. Many of experimental targets in OM III were deemed inconsistent. These are mostly for fuel-rich $\mathrm{C}_{4}$-hydrocarbon flames. The large spread of experimental target sets under those conditions clearly indicates that the relevant data should be carefully re-evaluated. 


\subsection{Data subset tests}

Given our understanding of the hierarchical nature of chemical kinetic reaction models, it is natural to ask, what is the impact of a particular set of data on constraining overall model predictions and their uncertainties? We explore this question here within the framework of MUM-PCE. When reducing the uncertainty of model predictions for $S_{u}^{\circ}$ the question arises as to which subset of $S_{u}^{\circ}$ targets impacts this uncertainty reduction to the largest extent. For example, in order to reduce the $2 \sigma$ uncertainty band for $n-\mathrm{C}_{4} \mathrm{H}_{10}$ flame predictions, will it be necessary to include all experimental targets of flames of $\mathrm{C}_{1-4}$ hydrocarbons or is there an optimal subset which will have the largest impact? A natural follow-on question is, what precision is needed in experimental measurements of $S_{u}^{\circ}$ to sufficiently constrain the uncertainty in predictions of laminar flame speed.

Table 5 lists a selection of case studies, ranging in target data size. Only the OM I data set was considered in the series of tests. While Test Ia contained only the $S_{u}^{\circ}$ 's of $\mathrm{CH}_{4}$ flames as targets, Ib considered $\mathrm{CH}_{4}$ and $\mathrm{C}_{2}$ hydrocarbons; Id used $\mathrm{C}_{1-3}$ hydrocarbons. In contrast, Ic* used only the dataset of the target fuel alone. That is, there is a Test Ic* for each fuel and the purpose of this model is to compare the uncertainty in $S_{u}^{\circ}$ predictions for a given fuel constrained by only its own measurements. OM I* used the data of $\mathrm{C}_{4} \mathrm{H}_{10}$ isomers $[19,67]$ in addition to the OM I data set.

We illustrate the principal findings of the aforementioned tests using $\mathrm{C}_{3} \mathrm{H}_{8}$ and $\mathrm{C}_{3} \mathrm{H}_{6}$ flames as examples. Figure 11 shows $1 \sigma$ uncertainty predicted for $S_{u}^{\circ}$ s of (a) $\mathrm{C}_{3} \mathrm{H}_{8} /$ air and (b) $\mathrm{C}_{3} \mathrm{H}_{6} /$ air mixtures over a range of $\phi$ 's at $T_{\mathrm{u}}=298 \mathrm{~K}$ and $p=1 \mathrm{~atm}$. It can be seen that qualitatively the model prediction uncertainty responds to dataset expansion in an expected manner: an increase in the datasets considered reduces the prediction uncertainty. At the quantitative level $\mathrm{C}_{3} \mathrm{H}_{6}$ responds to dataset expansion somewhat differently from $\mathrm{C}_{3} \mathrm{H}_{8}$. The prediction uncertainty for $\mathrm{C}_{3} \mathrm{H}_{6}$ flames decreased marginally from the prior model to Ia and Ib. Only when the data of $\mathrm{C}_{3} \mathrm{H}_{6}$ are introduced as targets (test Id) does the prediction uncertainty reduce to below $1 \mathrm{~cm} / \mathrm{s}$. On the other hand, the use of $\mathrm{C}_{1-2}$ hydrocarbon $S_{u}^{\circ}$ 's alone can reduce the prediction uncertainty for 
$\mathrm{C}_{3} \mathrm{H}_{8}$ efficiently. Clearly, the difference arises from the fact that the $S_{u}^{\circ}$ of $\mathrm{C}_{3} \mathrm{H}_{6}$ is more sensitive to fuel-specific reaction rates that that of $\mathrm{C}_{3} \mathrm{H}_{8}(c f$, Figs. $\mathrm{S} 10$ and $\mathrm{S} 11)$. The above observation can be made equally for $\mathrm{C}_{4}$ fuels, as shown in Fig. 12. Overall, our ability to predict the $S_{u}^{\circ}$ of saturated hydrocarbons is impacted mostly by the $S_{u}^{\circ}$ data of $\mathrm{C}_{1-2}$ hydrocarbon fuels, whereas for unsaturated $\mathrm{C}_{3-4}$ hydrocarbons fuel specific chemistry are more relevant and as such a more precise prediction of their $S_{u}^{\circ}$, s relies on the availability of the data for these fuels.

Figure 11 also shows that the prediction uncertainties of Test Ic* are comparable to those of Id. That is, precise predictions for $S_{u}^{\circ}$ 's of a particular fuel can be attained by using the data of that fuel alone, but the approach inevitably leads to the "many model" problem. Although a model optimized with the data of a particular fuel may achieve good predictions for that fuel, there is no reason to expect that such a model can make precise predictions for other fuels.

The impact of experimental uncertainty on the degree with which the measurement constrains the reaction model was examined next. The $2 \sigma$ uncertainty of $\mathrm{C}_{3} \mathrm{H}_{8} /$ air $S_{u}^{\circ}$ determined in the present study was estimated to be 1.0 to $1.2 \mathrm{~cm} / \mathrm{s}$ from the current study. Assuming that the uncertainty value includes a consideration of the systematic error of the experiment, reducing this uncertainty would, of course, improve the model precision. Table 6 illustrates the variation of the prediction uncertainty of $\mathrm{OM} \mathrm{I}$ as a function of the measurement uncertainty. An improvement of the experimental accuracy clearly tightens posterior model uncertainty, but we see diminishing return when the $2 \sigma$ uncertainty of the experimental $S_{u}^{\circ}$ value decreases to between \pm 2 and $\pm 1 \mathrm{~cm} / \mathrm{s}$. This result suggests that it would be beneficial to see convergence of measurements of the $S_{u}^{\circ}$ values to within around $\pm 2 \mathrm{~cm}$ or smaller across different laboratories, facilities and methods.

The final component of our tests illustrates the importance of foundation fuel chemistry on making accurate predictions for the flame properties of alcohols. For this purpose, USC Mech II was combined with the butanol submodel of Moss et al. [17]. A conservative uncertainty span of 2.5 was assigned to all butanol related reactions although the true uncertainty for some of these rate parameters could be larger. The prediction uncertainty values are shown in Fig. 13 for $S_{u}^{\circ}$ 's 
of normal-butanol $\left(n-\mathrm{C}_{4} \mathrm{H}_{9} \mathrm{OH}\right)$, iso-butanol $\left(i-\mathrm{C}_{4} \mathrm{H}_{9} \mathrm{OH}\right)$ and tert--butanol $\left(t-\mathrm{C}_{4} \mathrm{H}_{9} \mathrm{OH}\right)$ isomers in air. The prior model has a $1 \sigma$ prediction uncertainty of $3-5 \mathrm{~cm} / \mathrm{s}$ for $n-\mathrm{C}_{4} \mathrm{H}_{9} \mathrm{OH}$ and $i-\mathrm{C}_{4} \mathrm{H}_{9} \mathrm{OH}$, depending on $\phi$, whereas this uncertainty is somewhat smaller for $t-\mathrm{C}_{4} \mathrm{H}_{9} \mathrm{OH}$. The uncertainty was constrained quite efficiently by Test Ia, and is reduced further in cases $\mathrm{Ib}$ and Ic as $\mathrm{C}_{2-3} S_{u}^{\circ}$ data are added. The full OM I dataset is sufficient for constraining the prediction of butanol $S_{u}^{\circ}$ 's. The inclusion of the butanol $S_{u}^{\circ}$ data (Test I*), in fact, adds little to model improvements. The exercise just discussed illustrates an important point. Because of the hierarchical nature of reaction kinetics, what really matter is the availability of accurate combustion data for foundation, small hydrocarbon fuels if our interest is to make accurate predictions for the combustion properties of larger hydrocarbon fuels, including oxygenates. Wang and Sheen [22] have also demonstrated that $\mathrm{H}_{2} / \mathrm{CO}$ and $\mathrm{C}_{2} \mathrm{H}_{4}$ experimental dataset significantly reduces uncertainty in the predicted $n$-octane flame speeds using JetSurF 1.0 [68], in which USC Mech II is the foundational fuel chemistry model of JetSurF.

\subsection{Impact of model optimization on prediction of other combustion properties}

Perfectly stirred reactor (PSR) simulations are carried out here to demonstrate how the $S_{u}^{\circ}$ data can constrain model uncertainty and achieve more precise predictions for a different combustion phenomenon. The PSR simulates an idealized combustion problem in which fuel and oxidizer enter a reactor and the products leave the reactor in a steady state. The reactor is assumed to be spatially uniform. The rate of conversion of reactants to products is controlled by chemistry, not mixing.

Figure 14 shows $\mathrm{OH}$ mole fractions with respect to residence time in a PSR for the oxidation of an $n-\mathrm{C}_{4} \mathrm{H}_{9} \mathrm{OH} /$ air mixture at the constant temperature of $1500 \mathrm{~K}$, constant pressure of 1 atm, and $\phi=1.0$ along with associated uncertainties predicted by the prior model, the optimized OM II and OM II*. Two distinct branches are observed. At the short residence times, we have a weakly reactive state (lower branch) where chemistry is largely frozen. As the resident time is 


\section{Concluding remarks}

Laminar flame speeds were measured in the counterflow flame configuration for mixtures of air with propene, propane, 1,3-butadiene, 1-butene, 2-butene, iso-butene, $n$-butane, and isobutane at $298 \mathrm{~K}$ temperature and 1 atm pressure and over a range of equivalence ratios. This dataset supplements recently reported results [24, 25] and presents a self-consistent set of laminar flame speed data of $12 \mathrm{C}_{1-4}$ hydrocarbons of direct relevance to the development of foundation fuel chemistry models. Utilizing this and other data sets in the literature, a reaction model of foundation fuel chemistry (USC Mech II) was analyzed by the Method of Uncertainty Minimization using Polynomial Chaos Expansion (MUM-PCE) along with the experimental data. Key conclusions may be summarized as follows:

(1) Although the reported uncertainties of the flame speed data are relatively small within each laboratory, interlaboratory data scatter remains too large to reach consensus about the flame speed value of a particular fuel under a certain condition to within $\pm 2 \mathrm{~cm} / \mathrm{s}$;

(2) Nonetheless, laminar flame speed data are useful to constraining reaction model accuracy and precision if they are used jointly across a range of fuel sizes and structure, and equivalence ratio; (3) Among the $\mathrm{C}_{1-4}$ foundational hydrocarbons, the model accuracy and precision of $\mathrm{C}_{3-4}$ alkanes can be constrained efficiently by only the $\mathrm{C}_{1-2}$ flame speed data; whereas model accuracy and 
precision of unsaturated alkenes should require the data of the fuels themselves owing to a greater number of fuel specific reactions that can play a role in the overall oxidation process;

(4) Beyond the $\mathrm{C}_{1-4}$ foundational hydrocarbons, the model accuracy and precision for predictions of the laminar flame speeds of higher hydrocarbons and alcohols is expected to be constrained quite efficiently by the flame speeds of $\mathrm{C}_{1-4}$ foundation hydrocarbons, to an extent that there is little to no benefits to collect the flame speed values for these higher hydrocarbons other than a quick test of the accuracy of the nominal prediction by a model.

(5) The application of uncertainty minimization to a reaction model within a narrow range of constraints can lead to improvements of the precision of the model, both within and outside the conditions against which the model is constrained.

\section{Acknowledgements}

This material is based upon work partially supported as part of the CEFRC, an Energy Frontier Research Center funded by the U.S. Department of Energy, Office of Science, Office of Basic Energy Sciences under Award Number DE-SC0001198. Work was also partially supported by AFOSR under grant nos. FA9550-12-1-0472 and FA9550-16-1-0051. Dr. Peter Veloo would like to acknowledge support by the Thermal Sciences Practice at Exponent, Inc. 


\section{References}

[1] X. You, F.N. Egolfopoulos, H. Wang, Detailed and simplified kinetic models of $n$-dodecane oxidation: The role of fuel cracking in aliphatic hydrocarbon combustion, Proc. Combust. Inst. 32 (2009) 403-410.

[2] F.N. Egolfopoulos, D.L. Zhu, C.K. Law, Experimental and numerical determination of laminar flame speeds: Mixtures of C2-hydrocarbons with oxygen and nitrogen, Symp. (Int.) Combust. 23 (1991) 471-478.

[3] S.G. Davis, C.K. Law, Determination of and fuel structure effects on laminar flame speeds of C1 to C8 hydrocarbons, Combust. Sci. Technol. 140 (1998) 427-449.

[4] G. Jomaas, X.L. Zheng, D.L. Zhu, C.K. Law, Experimental determination of counterflow ignition temperatures and laminar flame speeds of C2-C3, Proc. Combust. Inst. 30 (2005) 193-200.

[5] D. Healy, D.M. Kalitan, C.J. Aul, E.L. Petersen, G. Bourque, H.J. Curran, Oxidation of C1C5 alkane quinternary natural gas mixtures at high pressures, Energy Fuels 24 (2010) 15211528.

[6] E. Ranzi, A. Frassoldati, R. Grana, A. Cuoci, T. Faravelli, A.P. Kelley, C.K. Law, Hierarchical and comparative kinetic modeling of laminar flame speeds of hydrocarbon and oxygenated fuels, Prog. Energy Combust. Sci. 38 (2012) 468-501.

[7] G. Dixon-Lewis, Kinetic mechanism, structure and properties of premixed flames in hydrogen-oxygen-nitrogen mixtures, Philos. Trans. R. Soc. London, Ser. A 292 (1979) 4599.

[8] G. Dixon-Lewis, Flame structure and flame reaction kinetics. II. transport phenomena in multicomponent systems, Proc. R. Soc. London, Ser. A 307 (1968) 111-135.

[9] J.A. Miller, R.E. Mitchell, M.D. Smooke, R.J. Kee, Toward a comprehensive chemical kinetic mechanism for the oxidation of acetylene: comparison of model predictions with results from flame and shock tube experiments, Proc. Combust. Inst. 19 (1982) 181-196.

[10] J. Warnatz, The structure of laminar alkane-, alkene-, and acetylene flames, Proc. Combust. Inst. 18 (1981) 369-384.

[11] C.K. Westbrook, F.L. Dryer, K.P. Schug, Numerical modeling of ethylene oxidation in laminar flames, Combust. Flame 52 (1983) 299-313.

[12] C.K. Westbrook, F.L. Dryer, Chemical kinetic modeling of hydrocarbon combustion, Prog. Energy Combust. Sci. 10 (1984) 1-57.

[13] C.K. Westbrook, F.L. Dryer, Prediction of laminar flame properties of methanol-air mixtures, Combust. Flame 37 (1980) 171-192.

[14] C.K. Westbrook, Chemical kinetics of hydrocarbon ignition in practical combustion systems, Proc. Combust. Inst. 28 (2000) 1563-1577.

[15] F.L. Dryer, K. Brezinsky, A flow reactor study of the oxidation of n-octane and iso-octane, Combust. Sci. Technol. 45 (1986) 199-212. 
16] S.G. Davis, C.K. Law, Laminar flame speeds and oxidation kinetics of iso-octane-air and nheptane-air flames, Symp. (Int.) Combust. 27 (1998) 521-527.

[17] J.T. Moss, A.M. Berkowitz, M.A. Oehlschlaeger, J. Biet, V. Warth, P.-A. Glaude, F. BattinLeclerc, An experimental and kinetic modeling study of the oxidation of the four isomers of butanol, J. Phys. Chem. A 112 (2008) 10843-10855.

[18] P.S. Veloo, F.N. Egolfopoulos, Studies of n-propanol, iso-propanol, and propane flames, Combust. Flame 158 (2011) 501-510.

[19] P.S. Veloo, F.N. Egolfopoulos, Flame propagation of butanol isomers/air mixtures, Proc. Combust. Inst. 33 (2011) 987-993.

[20] J.K. Lefkowitz, J.S. Heyne, S.H. Won, S. Dooley, H.H. Kim, F.M. Haas, S. Jahangirian, F.L. Dryer, Y. Ju, A chemical kinetic study of tertiary-butanol in a flow reactor and a counterflow diffusion flame, Combust. Flame 159 (2012) 968-978.

[21] M. Frenklach, H. Wang, M.J. Rabinowitz, Optimization and analysis of large chemical kinetic mechanisms using the solution mapping method-combustion of methane, Prog. Energy Combust. Sci. 18 (1992) 47-73.

[22] H. Wang, D.A. Sheen, Combustion kinetic model uncertainty quantification, propagation and minimization, Prog. Energy Combust. Sci. 47 (2015) 1-31.

[23] D.A. Sheen, H. Wang, The method of uncertainty quantification and minimization using polynomial chaos expansions, Combust. Flame 158 (2011) 2358-2374.

[24] O. Park, P.S. Veloo, F.N. Egolfopoulos, Flame studies of C2 hydrocarbons, Proc. Combust. Inst. 34 (2013) 711-718.

[25] O. Park, P.S. Veloo, N. Liu, F.N. Egolfopoulos, Combustion characteristics of alternative gaseous fuels, Proc. Combust. Inst. 33 (2011) 887-894.

[26] C.M. Vagelopoulos, F.N. Egolfopoulos, Direct experimental determination of laminar flame speeds, Proc. Combust. Inst. 27 (1998) 513-519.

[27] K.J. Bosschaart, L.P.H. De Goey, The laminar burning velocity of flames propagating in mixtures of hydrocarbons and air measured with the heat flux method, Combust. Flame 136 (2004) 261-269.

[28] F. Halter, T. Tahtouh, C. Mounaïm-Rousselle, Nonlinear effects of stretch on the flame front propagation, Combust. Flame 157 (2010) 1825-1832.

[29] M.I. Hassan, K.T. Aung, O.C. Kwon, G.M. Faeth, Properties of laminar premixed hydrocarbon/air flames at various pressures, J. Propul. Power 14 (1998) 479-488.

[30] W. Liu, A.P. Kelley, C.K. Law, Flame propagation and counterflow nonpremixed ignition of mixtures of methane and ethylene, Combust. Flame 157 (2010) 1027-1036.

[31] K. Kumar, G. Mittal, C.-J. Sung, C.K. Law, An experimental investigation of ethylene/O2/diluent mixtures: Laminar flame speeds with preheat and ignition delays at high pressures, Combust. Flame 153 (2008) 343-354.

[32] A.P. Kelley, Dynamics of expanding flames, Ph.D. Thesis, Princeton University, Princeton, NJ, USA, 2011. 
[44] Chemical-Kinetic Mechanisms for Combustion Applications. http://combustion.ucsd.edu.

[45] D. Healy, N.S. Donato, C.J. Aul, E.L. Petersen, C.M. Zinner, G. Bourque, H.J. Curran, Isobutane ignition delay time measurements at high pressure and detailed chemical kinetic simulations, Combust. Flame 157 (2010) 1540-1551.

[46] W.K. Metcalfe, S.M. Burke, S.S. Ahmed, H.J. Curran, A hierarchical and comparative kinetic modeling study of C1-C2 hydrocarbon and oxygenated fuels, Int. J. Chem. Kinet. 45 (2013) 638-675.

[47] S.M. Burke, W. Metcalfe, O. Herbinet, F. Battin-Leclerc, F.M. Haas, J. Santner, F.L. Dryer, H.J. Curran, An experimental and modeling study of propene oxidation. Part 1: Speciation measurements in jet-stirred and flow reactors, Combust. Flame 161 (2014) 2765-2784. 
[48] S.M. Burke, U. Burke, R. Mc Donagh, O. Mathieu, I. Osorio, C. Keesee, A. Morones, E.L. Petersen, W. Wang, T.A. DeVerter, An experimental and modeling study of propene oxidation. Part 2: Ignition delay time and flame speed measurements, Combust. Flame 162 (2015) 296-314.

[49] Y. Fenard, G. Dayma, F. Halter, F. Foucher, Z. Serinyel, P. Dagaut, Experimental and modeling study of the oxidation of 1-butene and cis-2-butene in a jet-stirred reactor and a combustion vessel, Energy Fuels 29 (2015) 1107-1118.

[50] R.J. Kee, J.F. Grcar, M.D. Smooke, J.A. Miller, A FORTRAN Program for Modeling Steady Laminar One-Dimensional Premixed Flames, Report No. SAND85-8240, Sandia National Laboratories, Livermore, CA, USA, 1986.

[51] R.J. Kee, F.M. Rupley, J.A. Miller, Chemkin-II: A Fortran Chemical Kinetics Package for the Analysis of Gas-Phase Chemical KineticS, Report No. SAND89-8009, Sandia National Laboratories, Livermore, CA, USA, 1989.

[52] R.J. Kee, J. Warnatz, J.A. Miller, A FORTRAN Computer Code Package for the Evaluation of Gas- Phase Viscosities, Conductivities and Diffusion Coefficients, Report No. SAND838209, Sandia National Laboratories, Livermore, CA, USA, 1983.

[53] P. Middha, H. Wang, First-principle calculation for the high-temperature diffusion coefficients of small pairs: the H-Ar Case, Combust. Theor. Model. 9 (2005) 353-363.

[54] Y. Dong, A.T. Holley, M.G. Andac, F.N. Egolfopoulos, S.G. Davis, P. Middha, H. Wang, Extinction of premixed H2/air flames: Chemical kinetics and molecular diffusion effects, Combust. Flame 142 (2005) 374-387.

[55] M.T. Reagan, H.N. Najm, R.G. Ghanem, O.M. Knio, Uncertainty quantification in reactingflow simulations through non-intrusive spectral projection, Combust. Flame 132 (2003) 545-555.

[56] M.T. Reagan, H.N. Najm, B.J. Debusschere, O.P. Le Maitre, M. Knio, R.G. Ghanem, Spectral stochastic uncertainty quantification in chemical systems, Combust. Theor. Model. 8 (2004) 607-632.

[57] M.T. Reagan, H.N. Najm, P.P. Pebay, O.M. Knio, R.G. Ghanem, Quantifying uncertainty in chemical systems modeling, Int. J. Chem. Kinet. 37 (2005) 368-382.

[58] S.G. Davis, A.B. Mhadeshwar, D.G. Vlachos, H. Wang, A new approach to response surface development for detailed gas-phase and surface reaction kinetic model optimization, Int. J. Chem. Kinet. 36 (2004) 94-106.

[59] C.K. Law, F. Wu, F.N. Egolfopoulos, V. Gururajan, H. Wang, On the Rational Interpretation of Data on Laminar Flame Speeds and Ignition Delay Times, Combust. Sci. Technol. 187 (2015) 27-36.

[60] K. Braman, T.A. Oliver, V. Raman, Bayesian analysis of syngas chemistry models, Combust. Theor. Model. 17 (2013) 858-887.

[61] T. Turányi, T. Nagy, I.G. Zsély, M. Cserháti, T. Varga, B.T. Szabó, I. Sedyó, P.T. Kiss, A. Zempléni, H.J. Curran, Determination of rate parameters based on both direct and indirect measurements, Int. J. Chem. Kinet. 44 (2012) 284-302. 
[62] T. Varga, T. Nagy, C. Olm, I.G. Zsély, R. Pálvölgyi, É. Valkó, G. Vincze, M. Cserháti, H.J. Curran, T. Turányi, Optimization of a hydrogen combustion mechanism using both direct and indirect measurements, Proc. Combust. Inst. 35 (2015) 589-596.

[63] J. Zádor, I.G. Zsély, T. Turányi, M. Ratto, S. Tarantola, A. Saltelli, Local and Global Uncertainty Analyses of a Methane Flame Model, J. Phys. Chem. A 109 (2005) 9795-9807.

[64] P. Zhao, W. Yuan, H. Sun, Y. Li, A.P. Kelley, X. Zheng, C.K. Law, Laminar flame speeds, counterflow ignition, and kinetic modeling of the butene isomers, Proc. Combust. Inst. 35 (2015) 309-316.

[65] A.W. Jasper, S.J. Klippenstein, L.B. Harding, B. Ruscic, Kinetics of the reaction of methyl radical with hydroxyl radical and methanol decomposition, J. Phys. Chem. A 111 (2007) 3932-3950.

[66] Z. Hong, D.F. Davidson, K.-Y. Lam, R.K. Hanson, A shock tube study of the rate constants of $\mathrm{HO} 2$ and $\mathrm{CH} 3$ reactions, Combust. Flame 159 (2012) 3007-3013.

[67] P.S. Veloo, Y.L. Wang, F.N. Egolfopoulos, C.K. Westbrook, A comparative experimental and computational study of methanol, ethanol, and n-butanol flames, Combust. Flame 157 (2010) 1989-2004.

[68] E.D. B. Sirjean, D.A. Sheen, X.-Q. You, C.J. Sung, A.T. Holley, F.N. Egolfopoulos, H. Wang, S.S. Vasu, D.F. Davidson, R.K. Hanson, H. Pitsch, C.T. Bowman, A. Kelley, C.K. Law, W. Tsang, N.P.Cernansky, D.L. Miller, A. Violi, R.P. Lindstedt, A high-temperature chemical kinetic model of n-alkane oxidation, JetSurF version 1.0. http://web.stanford.edu/group/haiwanglab/JetSurF/JetSurF1.0/index.html. 
Table 1. Summary of reaction models tested

\begin{tabular}{lccc}
\hline Model name/group & $\begin{array}{c}\text { Abbreviated } \\
\text { name }^{a}\end{array}$ & Year & Source \\
\hline USC-Mech II & -- & 2007 & {$[33]$} \\
Nancy & Model n & 2008 & {$[17]$} \\
San Diego Mech & Model s & 2009 & {$[44]$} \\
Galway & Model g & 2010 & {$[5,45]$} \\
Aramco Mech1.3 & Model a-1 & 2013 & {$[46]$} \\
Aramco Mech - Propene & Model a-2 & 2015 & {$[47,48]$} \\
Orléans & Model o & 2015 & {$[49]$} \\
\hline${ }^{a}$ The manuscript text will refer a particular model by its abbreviated name
\end{tabular}

Table 2. List of datasets tested for model optimization.

\begin{tabular}{cccc}
\hline & \multicolumn{4}{c}{ Data set $^{{ }^{a}}$} \\
\cline { 2 - 4 } Mixture & OM I & OM II & OM III \\
\hline $\mathrm{CH}_{4} /$ air & {$[25]$} & {$[25-28]$} & {$[25-28]$} \\
$\mathrm{C}_{2} \mathrm{H}_{2} / \mathrm{O}_{2} / \mathrm{N}_{2}{ }^{\mathrm{b}}$ & {$[24]$} & {$[2,24]$} & {$[2,24]$} \\
$\mathrm{C}_{2} \mathrm{H}_{4} /$ air & {$[24]$} & {$[4,24,29,30]$} & {$[4,24,29-31]$} \\
$\mathrm{C}_{2} \mathrm{H}_{6} /$ air & {$[24]$} & {$[4,24,26,27]$} & {$[4,24,26,27]$} \\
$\mathrm{C}_{3} \mathrm{H}_{8} /$ air & $\mathrm{c}$ & $\mathrm{c},[4,26,27]$ & $\mathrm{c},[4,26,27]$ \\
$\mathrm{C}_{3} \mathrm{H}_{6} /$ air & $\mathrm{c}$ & $\mathrm{c},[4]$ & $\mathrm{c},[3,4]$ \\
$n-\mathrm{C}_{4} \mathrm{H}_{10} /$ air & $\mathrm{c}$ & $\mathrm{c},[27]$ & $\mathrm{c},[3,27]$ \\
$i-\mathrm{C}_{4} \mathrm{H}_{10} /$ air & $\mathrm{c}$ & $\mathrm{c},[27]$ & $\mathrm{c},[3,27]$ \\
$1-\mathrm{C}_{4} \mathrm{H}_{8} /$ air & $\mathrm{c}$ & $\mathrm{c}$ & $\mathrm{c},[3]$ \\
$2-\mathrm{C}_{4} \mathrm{H}_{8} /$ air & $\mathrm{c}$ & $\mathrm{c}$ & $\mathrm{c}$ \\
$i-\mathrm{C}_{4} \mathrm{H}_{8} /$ air & $\mathrm{c}$ & $\mathrm{c}$ & $\mathrm{c},[3]$ \\
$1,3-\mathrm{C}_{4} \mathrm{H}_{6} /$ air & $\mathrm{c}$ & $\mathrm{c}$ & $\mathrm{c},[3]$ \\
\hline
\end{tabular}

${ }^{\mathrm{a}}$ OM I: data from refs. [24, 25] and this work; OM II: all literature data except for those of [3]; OM III : all data. ${ }^{\mathrm{b}} 13 \% \mathrm{O}_{2}+87 \% \mathrm{~N}_{2}$ (mol). ${ }^{\mathrm{c}}$ this work. 
Table 3. Experimental $S_{u}^{\circ}(\mathrm{cm} / \mathrm{s})$ target values and their associated $2 \sigma$ uncertainties.

\begin{tabular}{|c|c|c|c|c|c|c|c|c|c|c|c|}
\hline \multirow{2}{*}{$\begin{array}{c}\text { Fuel }^{\mathrm{a}} \\
\mathrm{CH}_{4}\end{array}$} & $\phi$ & & & & & & Fuel $^{\mathrm{a}}$ & \multicolumn{2}{|l|}{$\phi$} & & \multirow[b]{2}{*}[3]{} \\
\hline & & [25] & [27] & [26] & [28] & & $n-\mathrm{C}_{4} \mathrm{H}_{10}$ & & $\mathrm{~b}$ & [27] & \\
\hline & 0.7 & $18.2 \pm 1.3$ & $15.1 \pm 1$ & $15.8 \pm 2$ & $17.2 \pm 2$ & & & 0.7 & $21.1 \pm 1.1$ & $19.08 \pm 1$ & $20.2 \pm 2$ \\
\hline & 0.8 & $25.4 \pm 1.5$ & $23.7 \pm 1$ & $24.1 \pm 2$ & $24.9 \pm 2$ & & & 0.8 & $28.2 \pm 1.0$ & $26.84 \pm 1$ & $26.8 \pm 2$ \\
\hline & 1.0 & $35.9 \pm 1.0$ & & $36.5 \pm 2$ & $34.7 \pm 2$ & & & 1.0 & $36.9 \pm 1.0$ & $37.11 \pm 1$ & $38.0 \pm 2$ \\
\hline & 1.2 & $31.2 \pm 1.3$ & $33.8 \pm 1$ & $31.8 \pm 2$ & $31.2 \pm 2$ & & & 1.2 & $34.3 \pm 1.1$ & $36.71 \pm 1$ & $37.9 \pm 2$ \\
\hline & 1.3 & $20.8 \pm 1.4$ & $26.5 \pm 1$ & $20.8 \pm 2$ & $21.2 \pm 2$ & & & 1.4 & $18.5 \pm 1.5$ & $23.68 \pm 1$ & $24.8 \pm 2$ \\
\hline $\mathrm{C}_{2} \mathrm{H}_{2}$ & & [24] & [2] & & & & $i-\mathrm{C}_{4} \mathrm{H}_{10}$ & & $\mathrm{~b}$ & [27] & [3] \\
\hline & 0.7 & $19.7 \pm 1.0$ & $19.1 \pm 2$ & & & & & 07 & $197+11$ & $165+1$ & $186+2$ \\
\hline & 0.8 & $29.3 \pm 1.0$ & $30.1 \pm 2$ & & & & & $\begin{array}{l}0.1 \\
0.8\end{array}$ & $\begin{array}{l}19.7 \pm 1.1 \\
25.8 \pm 1.0\end{array}$ & $\begin{array}{l}10.3 \pm 1 \\
23.3 \pm 1\end{array}$ & $\begin{array}{l}18.0 \pm 2 \\
24.9 \pm 2\end{array}$ \\
\hline & 1.0 & $44.4 \pm 1.3$ & $45.9 \pm 2$ & & & & & $\begin{array}{l}.0 \\
1.0\end{array}$ & $33.4 \pm 1.0$ & $33.4 \pm 1$ & $35.4 \pm 2$ \\
\hline & 1.2 & $50.3 \pm 1.6$ & $51.7 \pm 2$ & & & & & 1.2 & $30.3 \pm 1.0$ & $33.4 \pm 1$ & $34.9 \pm 2$ \\
\hline & 1.4 & $39.8 \pm 1.3$ & $40.1 \pm 2$ & & & & & 1.4 & $16.8 \pm 1.3$ & $20.4 \pm 1$ & $22.9 \pm 2$ \\
\hline & 1.6 & $23.0 \pm 0.8$ & $23.2 \pm 2$ & & & & & & & & \\
\hline $\mathrm{C}_{2} \mathrm{H}_{4}$ & & [24] & [4] & [29] & [30] & [31] & $1,3-\mathrm{C}_{4} \mathrm{H}_{6}$ & & b & [3] & \\
\hline & 0.7 & $36.9 \pm 1.5$ & $35.1 \pm 2$ & & & $43.2 \pm 2$ & & 0.7 & $28.5 \pm 1.0$ & $27.4 \pm 2$ & \\
\hline & 0.8 & $47.0 \pm 1.2$ & $48.8 \pm 2$ & & $49.3 \pm 2$ & $53.7 \pm 2$ & & 0.8 & $39.5 \pm 1.0$ & $37.5 \pm 2$ & \\
\hline & 1.0 & $64.6 \pm 1.2$ & $62.3 \pm 2$ & $64.7 \pm 2$ & $65.7 \pm 2$ & $68.5 \pm 2$ & & 1.0 & $51.0 \pm 1.1$ & $51.5 \pm 2$ & \\
\hline & 1.2 & $66.5 \pm 1.4$ & $63.4 \pm 2$ & $64.4 \pm 2$ & $66.0 \pm 2$ & $70.6 \pm 2$ & & 1.2 & $52.0 \pm 1.5$ & $55.7 \pm 2$ & \\
\hline & 1.4 & $51.6 \pm 1.7$ & $52.0 \pm 2$ & $57.9 \pm 2$ & & $58.8 \pm 2$ & & 1.4 & $38.0 \pm 1.5$ & $45.1 \pm 2$ & \\
\hline $\mathrm{C}_{2} \mathrm{H}_{6}$ & & [24] & [4] & [27] & [26] & & $1-\mathrm{C}_{4} \mathrm{H}_{8}$ & & $\mathrm{~b}$ & [3] & \\
\hline & 0.7 & $20.0 \pm 1.6$ & & & & & & 0.7 & $25.2 \pm 1.2$ & $22.8 \pm 2$ & \\
\hline & 0.8 & $29.1 \pm 1.2$ & $28.4 \pm 2$ & $29.7 \pm 1$ & & & & 0.8 & $31.8 \pm 1.3$ & $31.9 \pm 2$ & \\
\hline & 1.0 & $39.1 \pm 1.2$ & $38.1 \pm 2$ & $40.8 \pm 1$ & $40.2 \pm 2$ & & & 1.0 & $41.5 \pm 1.2$ & $43.9 \pm 2$ & \\
\hline & 1.2 & $37.5 \pm 1.9$ & $38.5 \pm 2$ & $40.5 \pm 1$ & $40.9 \pm 2$ & & & 1.2 & $40.0 \pm 1.5$ & $45.8 \pm 2$ & \\
\hline & 1.4 & $22.8 \pm 1.5$ & $26.3 \pm 2$ & $26.7 \pm 1$ & $26.2 \pm 2$ & & & 1.4 & $25.5 \pm 1.5$ & $34.7 \pm 2$ & \\
\hline $\mathrm{C}_{3} \mathrm{H}_{8}$ & & b & [4] & [27] & [26] & & $i-\mathrm{C}_{4} \mathrm{H}_{8}$ & & b & [3] & \\
\hline & 0.7 & $22.5 \pm 1.0$ & $21.7 \pm 2$ & $20.2 \pm 1$ & $20.3 \pm 2$ & & & 0.7 & $17.3 \pm 1.0$ & $20.1 \pm 2$ & \\
\hline & 0.8 & $30.0 \pm 1.0$ & $29.9 \pm 2$ & $28.5 \pm 1$ & $30.0 \pm 2$ & & & 0.8 & $25.8 \pm 1.0$ & $25.9 \pm 2$ & \\
\hline & 1.0 & $38.3 \pm 1.0$ & $41.4 \pm 2$ & $39.4 \pm 1$ & $39.0 \pm 2$ & & & 1.0 & $35.0 \pm 1.6$ & $37.8 \pm 2$ & \\
\hline & 1.2 & $36.0 \pm 1.2$ & $39.5 \pm 2$ & $38.4 \pm 1$ & $38.8 \pm 2$ & & & 1.2 & $32.5 \pm 1.1$ & $39.1 \pm 2$ & \\
\hline & 1.4 & $18.7 \pm 1.2$ & $26.7 \pm 2$ & $23.8 \pm 1$ & $24.5 \pm 2$ & & & 1.3 & $17.8 \pm 1.5$ & $35.6 \pm 2$ & \\
\hline $\mathrm{C}_{3} \mathrm{H}_{6}$ & & $\mathrm{~b}$ & [4] & [3] & & & $2-\mathrm{C}_{4} \mathrm{H}_{8}$ & & $\mathrm{~b}$ & & \\
\hline & 0.7 & $24.4 \pm 0.8$ & $20.1 \pm 2$ & $20.6 \pm 2$ & & & & 0.7 & $22.2 \pm 1.3$ & & \\
\hline & 0.8 & $32.5 \pm 0.8$ & $28.7 \pm 2$ & $29.9 \pm 2$ & & & & 0.8 & $30.7 \pm 1.3$ & & \\
\hline & 1.0 & $42.0 \pm 1.0$ & $40.3 \pm 2$ & $41.5 \pm 2$ & & & & 1.0 & $39.5 \pm 1.6$ & & \\
\hline & 1.2 & $40.5 \pm 1.2$ & $40.7 \pm 2$ & $43.9 \pm 2$ & & & & 1.2 & $36.1 \pm 1.5$ & & \\
\hline & 1.4 & $25.5 \pm 1.3$ & $27.4 \pm 2$ & $33.1 \pm 2$ & & & & 1.4 & $21.2 \pm 1.5$ & & \\
\hline
\end{tabular}

\footnotetext{
${ }^{a}$ Fuels in air except acetylene $\left(\mathrm{C}_{2} \mathrm{H}_{2}\right)$ with dilute air: $13 \% \mathrm{O}_{2}+87 \% \mathrm{~N}_{2}$ (mol). ${ }^{b}$ This work.
} 
Table 4. Uncertainty spans and ratios of optimized-to-nominal rate coefficients for selected reactions of OM I and OM II.

\begin{tabular}{|c|c|c|c|c|}
\hline & Reactions & $\operatorname{Span}, f^{\mathrm{a}}$ & OM I & OM II \\
\hline 1 & $\mathrm{H}+\mathrm{O}_{2} \leftrightarrow \mathrm{O}+\mathrm{OH}$ & 1.2 & 0.94 & 1.02 \\
\hline 12 & $\mathrm{H}+\mathrm{O}_{2}+\mathrm{M} \leftrightarrow \mathrm{HO}_{2}+\mathrm{M}$ & 1.2 & 1.05 & 1.06 \\
\hline 17 & $\mathrm{H}+\mathrm{O}_{2}+\mathrm{H}_{2} \mathrm{O} \leftrightarrow \mathrm{HO}_{2}+\mathrm{H}_{2} \mathrm{O}$ & 2.5 & 1.03 & 1.04 \\
\hline 34 & $\mathrm{CO}+\mathrm{OH} \leftrightarrow \mathrm{CO}_{2}+\mathrm{H}($ high $T)$ & 1.2 & 0.92 & 0.94 \\
\hline 35 & $\mathrm{CO}+\mathrm{OH} \leftrightarrow \mathrm{CO}_{2}+\mathrm{H}($ low $T)$ & 1.2 & 0.96 & 0.95 \\
\hline 38 & $\mathrm{HCO}+\mathrm{H} \leftrightarrow \mathrm{CO}+\mathrm{H}_{2}$ & 2 & 0.94 & 0.71 \\
\hline 41 & $\mathrm{HCO}+\mathrm{OH} \leftrightarrow \mathrm{CO}+\mathrm{H}_{2} \mathrm{O}$ & 3 & 0.82 & 0.88 \\
\hline 42 & $\mathrm{HCO}+\mathrm{M} \leftrightarrow \mathrm{CO}+\mathrm{H}+\mathrm{M}$ & 4 & 1.42 & 1.54 \\
\hline 43 & $\mathrm{HCO}+\mathrm{H}_{2} \mathrm{O} \leftrightarrow \mathrm{CO}+\mathrm{H}+\mathrm{H}_{2} \mathrm{O}$ & 2 & 1.21 & 1.07 \\
\hline 53 & $\mathrm{CH}+\mathrm{O}_{2} \leftrightarrow \mathrm{HCO}+\mathrm{O}$ & 10 & 3.75 & 2.26 \\
\hline 91 & $\mathrm{CH}_{3}+\mathrm{H}+\mathrm{M} \leftrightarrow \mathrm{CH}_{4}+\mathrm{M}$ & 2 & 1.11 & 0.93 \\
\hline 92 & $\mathrm{CH}_{3}+\mathrm{O} \leftrightarrow \mathrm{CH}_{2} \mathrm{O}+\mathrm{H}$ & 2 & 0.71 & 1.18 \\
\hline 93 & $\mathrm{CH}_{3}+\mathrm{OH}+\mathrm{M} \leftrightarrow \mathrm{CH}_{3} \mathrm{OH}+\mathrm{M}$ & 5 & 0.76 & 0.92 \\
\hline 95 & $\mathrm{CH}_{3}+\mathrm{OH} \leftrightarrow \mathrm{CH}_{2}(\mathrm{~s})+\mathrm{H}_{2} \mathrm{O}$ & 5 & 1.50 & 0.47 \\
\hline 99 & $\mathrm{CH}_{3}+\mathrm{HO}_{2} \leftrightarrow \mathrm{CH}_{3} \mathrm{O}+\mathrm{OH}$ & 3 & 1.07 & 0.70 \\
\hline 108 & $\mathrm{CH}_{3}+\mathrm{CH}_{3} \leftrightarrow \mathrm{C}_{2} \mathrm{H}_{5}+\mathrm{H}$ & 5 & 2.44 & 1.24 \\
\hline 152 & $\mathrm{HCCO}+\mathrm{O}_{2} \leftrightarrow \mathrm{OH}+2 \mathrm{CO}$ & 5 & 0.35 & 0.29 \\
\hline 197 & $\mathrm{C}_{2} \mathrm{H}_{3}+\mathrm{O}_{2} \leftrightarrow \mathrm{CH}_{2} \mathrm{CHO}+\mathrm{O}$ & 4 & 1.56 & 1.32 \\
\hline 198 & $\mathrm{C}_{2} \mathrm{H}_{3}+\mathrm{O}_{2} \leftrightarrow \mathrm{HCO}+\mathrm{CH}_{2} \mathrm{O}$ & 4 & 0.69 & 0.63 \\
\hline 252 & $\mathrm{C}_{2} \mathrm{H}_{4}+\mathrm{H}+\mathrm{M} \leftrightarrow \mathrm{C}_{2} \mathrm{H}_{5}+\mathrm{M}$ & 3 & 0.47 & 0.34 \\
\hline 268 & $\mathrm{C}_{2} \mathrm{H}_{4}+\mathrm{C}_{2} \mathrm{H}_{3} \leftrightarrow \mathrm{C}_{4} \mathrm{H}_{7}$ & 2 & 0.69 & 0.79 \\
\hline 328 & $a-\mathrm{C}_{3} \mathrm{H}_{5}+\mathrm{H}+\mathrm{M} \leftrightarrow \mathrm{C}_{3} \mathrm{H}_{6}+\mathrm{M}$ & 3 & 0.66 & 0.59 \\
\hline 337 & $a-\mathrm{C}_{3} \mathrm{H}_{5}+\mathrm{HO}_{2} \leftrightarrow \mathrm{OH}+\mathrm{C}_{2} \mathrm{H}_{3}+\mathrm{CH}_{2} \mathrm{O}$ & 3 & 1.48 & 1.28 \\
\hline 442 & $i-\mathrm{C}_{4} \mathrm{H}_{3}+\mathrm{H} \leftrightarrow \mathrm{C}_{4} \mathrm{H}_{2}+\mathrm{H}_{2}$ & 10 & 1.42 & 1.80 \\
\hline 483 & $\mathrm{C}_{4} \mathrm{H}_{6}+\mathrm{H} \leftrightarrow i-\mathrm{C}_{4} \mathrm{H}_{5}+\mathrm{H}_{2}$ & 5 & 5.0 & 4.07 \\
\hline 484 & $\mathrm{C}_{4} \mathrm{H}_{6}+\mathrm{H} \leftrightarrow \mathrm{C}_{2} \mathrm{H}_{4}+\mathrm{C}_{2} \mathrm{H}_{3}$ & 2 & 0.80 & 0.83 \\
\hline 490 & $\mathrm{C}_{4} \mathrm{H}_{6}+\mathrm{O} \leftrightarrow \mathrm{C}_{2} \mathrm{H}_{4}+\mathrm{C}_{2} \mathrm{H}_{3}$ & 3 & 0.72 & 0.81 \\
\hline 491 & $\mathrm{C}_{4} \mathrm{H}_{6}+\mathrm{OH} \leftrightarrow n-\mathrm{C}_{4} \mathrm{H}_{5}+\mathrm{H}_{2} \mathrm{O}$ & 3 & 1.59 & 1.53 \\
\hline 492 & $\mathrm{C}_{4} \mathrm{H}_{6}+\mathrm{OH} \leftrightarrow i-\mathrm{C}_{4} \mathrm{H}_{5}+\mathrm{H}_{2} \mathrm{O}$ & 5 & 0.46 & 0.45 \\
\hline 549 & $i-\mathrm{C}_{4} \mathrm{H}_{7}+\mathrm{H}+\mathrm{M} \leftrightarrow i-\mathrm{C}_{4} \mathrm{H}_{8}+\mathrm{M}$ & 2 & 0.81 & 0.73 \\
\hline 565 & $2-\mathrm{C}_{4} \mathrm{H}_{8}+\mathrm{H}+\mathrm{M} \leftrightarrow s-\mathrm{C}_{4} \mathrm{H}_{9}+\mathrm{M}$ & 3 & 1.73 & 1.05 \\
\hline 566 & $2-\mathrm{C}_{4} \mathrm{H}_{8}+\mathrm{H} \leftrightarrow \mathrm{C}_{4} \mathrm{H}_{7}+\mathrm{H}_{2}$ & 3 & 0.33 & 0.45 \\
\hline 567 & $2-\mathrm{C}_{4} \mathrm{H}_{8}+\mathrm{O} \leftrightarrow \mathrm{C}_{2} \mathrm{H}_{4}+\mathrm{CH}_{3} \mathrm{CHO}$ & 3 & 3.0 & 2.86 \\
\hline 573 & $i-\mathrm{C}_{4} \mathrm{H}_{8}+\mathrm{H} \leftrightarrow i-\mathrm{C}_{4} \mathrm{H}_{7}+\mathrm{H}_{2}$ & 3 & 0.76 & 0.73 \\
\hline 578 & $i-\mathrm{C}_{4} \mathrm{H}_{8}+\mathrm{OH} \leftrightarrow i-\mathrm{C}_{4} \mathrm{H}_{7}+\mathrm{H}_{2} \mathrm{O}$ & 3 & 0.83 & 0.75 \\
\hline 592 & $\mathrm{C}_{3} \mathrm{H}_{6}+\mathrm{CH}_{3}+\mathrm{M} \leftrightarrow s-\mathrm{C}_{4} \mathrm{H}_{9}+\mathrm{M}$ & 2 & 1.30 & 1.37 \\
\hline 634 & $\mathrm{C}_{4} \mathrm{H}_{10}+\mathrm{H}+\mathrm{M} \leftrightarrow \mathrm{s}-\mathrm{C}_{4} \mathrm{H}_{9}+\mathrm{H}_{2}$ & 3 & 1.30 & 1.61 \\
\hline
\end{tabular}


Table 5. Summary of test cases.

\begin{tabular}{|c|c|}
\hline No. & Target data \\
\hline Ia & $\mathrm{CH}_{4}$ \\
\hline $\mathrm{Ib}$ & All $\mathrm{C}_{1-2}$ hydrocarbons \\
\hline Ic* & Single, target fuel (see text) \\
\hline Id & All $\mathrm{C}_{1-3}$ hydrocarbons \\
\hline I & All $\mathrm{C}_{1-4}$ hydrocarbons $^{\mathrm{a}}$ \\
\hline$I^{*}($ or II*) & $\mathrm{OM} \mathrm{I}$ (or II) + three butanol isomers \\
\hline
\end{tabular}

Table 6. Relationship between measurement and model uncertainties of the $\mathrm{C}_{3} \mathrm{H}_{8}$ /air mixture at $\phi=1.2$. Values listed are $2 \sigma$ uncertainty.

\begin{tabular}{cc}
\hline Experimental & Model \\
\hline$\infty$ & 7.4 \\
5.0 & 3.1 \\
4.0 & 2.6 \\
2.0 & 1.7 \\
1.0 & 1.2 \\
\hline
\end{tabular}



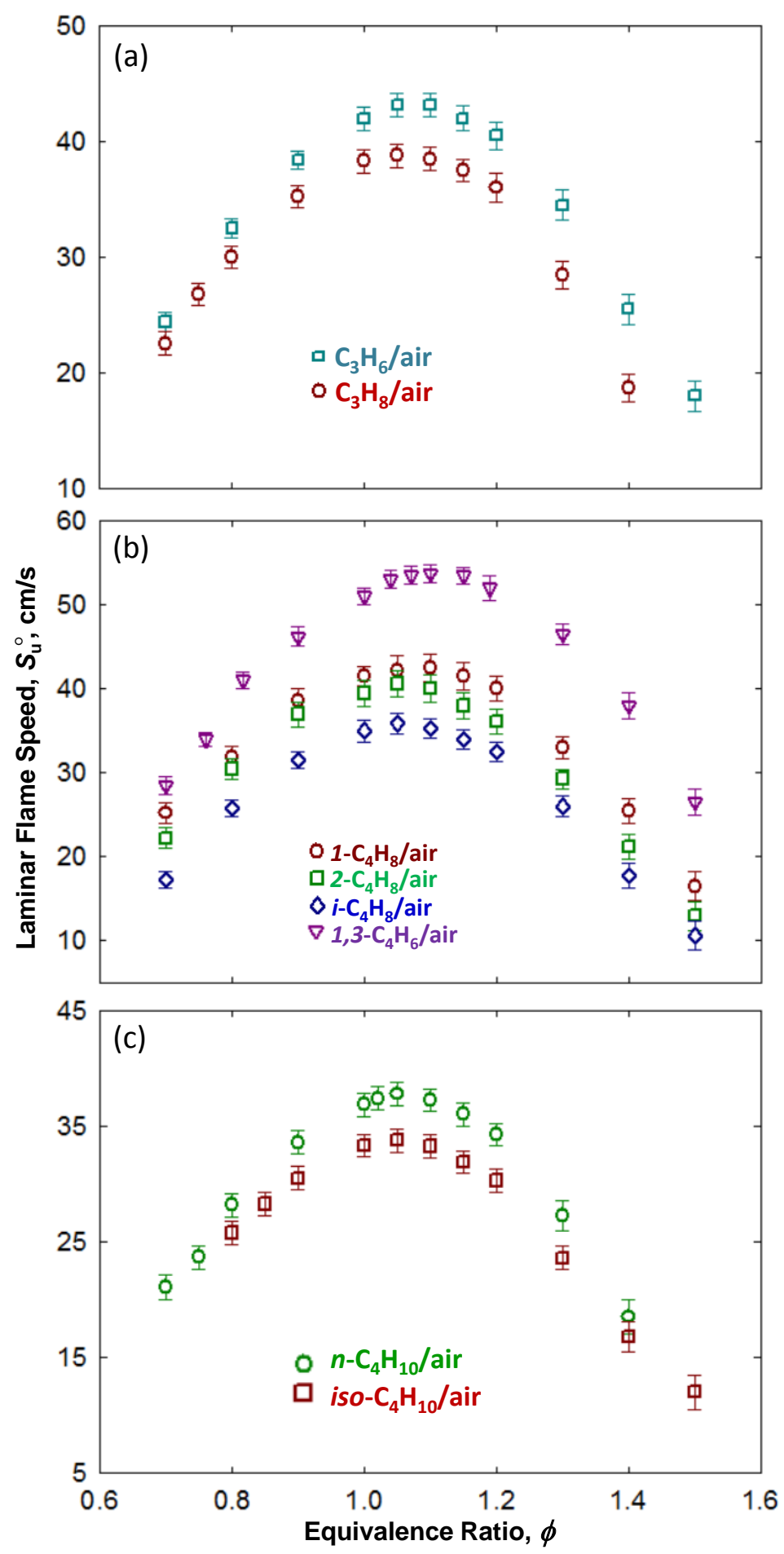

Figure 1. $S_{u}^{\circ}$ 's of $\mathrm{C}_{3-4}$ hydrocarbons/air mixtures determined in the current study at $T_{\mathrm{u}}=298 \mathrm{~K}$ and $p=1$ atm. The error bars represent $2 \sigma$ uncertainty. The data are provided in SPM. 

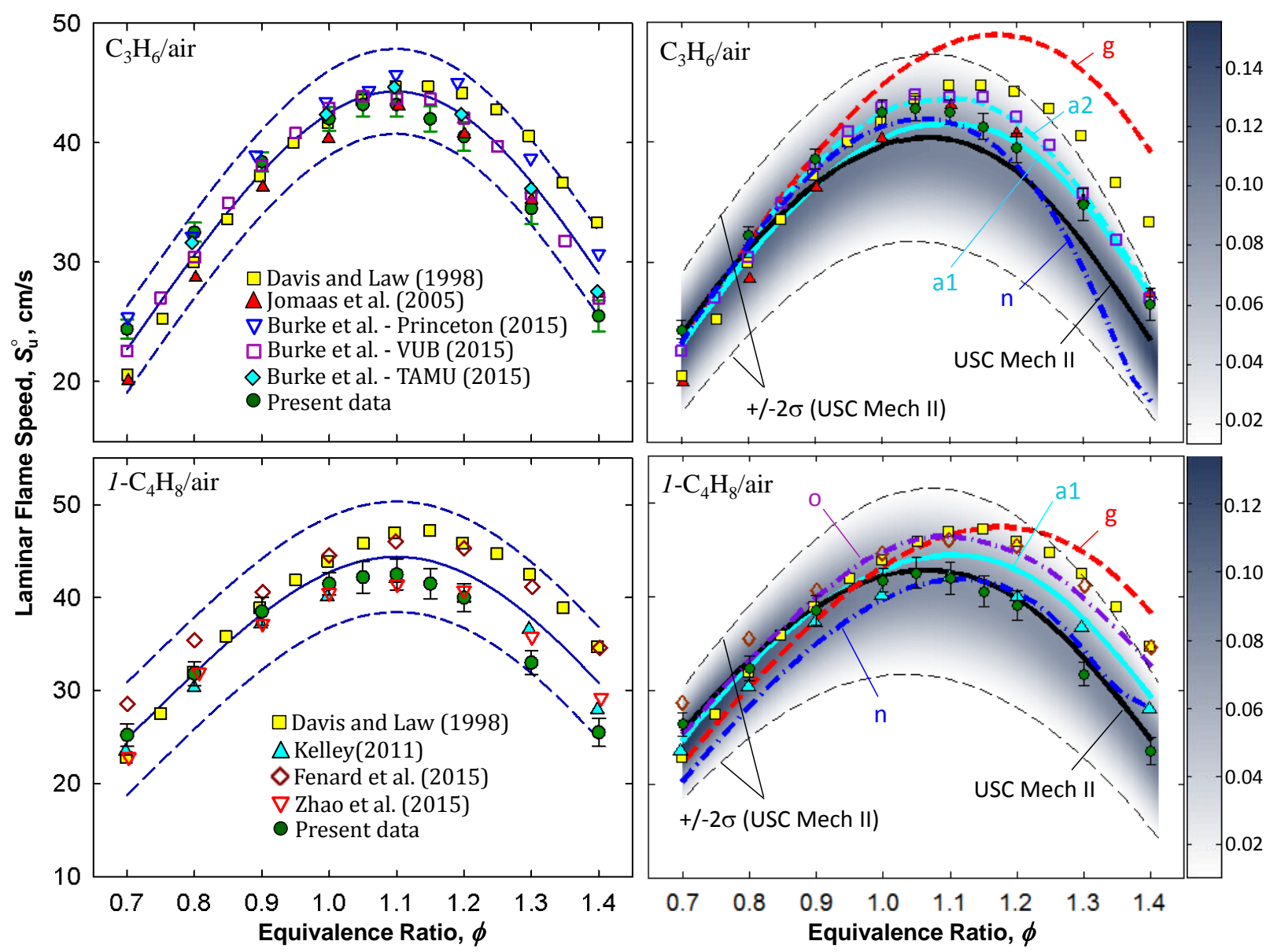

Figure 2. Left panel: selected experimental data (symbols) and results of uncertainty analysis (solid lines, nominal fits to data; dashed lines: $2 \sigma$ uncertainty) of $S_{u}^{\circ}$ of $\mathrm{C}_{3} \mathrm{H}_{6} /$ air and $1-\mathrm{C}_{4} \mathrm{H}_{8} /$ air mixtures at $p=1 \mathrm{~atm}$ and $T_{u}=298 \mathrm{~K}$. Right panel: Selected experimental (symbols) and computed (lines) $S_{u}^{\circ}$ also at $p=1 \mathrm{~atm}$ and $T_{\mathrm{u}}=298 \mathrm{~K}$. The error bars represent $2 \sigma$ uncertainty of the data. The grey level indicates the normalized probability density function of $S_{u}^{\circ}$ predicted by USC Mech II. See Table 1 for the labels of the models used for predictions. Symbols: $O$ present data; $\square$ Davis and Law, 1998 [3]; $\triangle$ Jomaas et al., 2005 [4]; $\nabla, \square, \diamond$ Burke et al., 2015 [48]; $\triangle$ Kelley, 2011 [32]; $\diamond$ Fenard et al., 2015 [49]; $\nabla$ Zhao et al., 2015 [64]. 

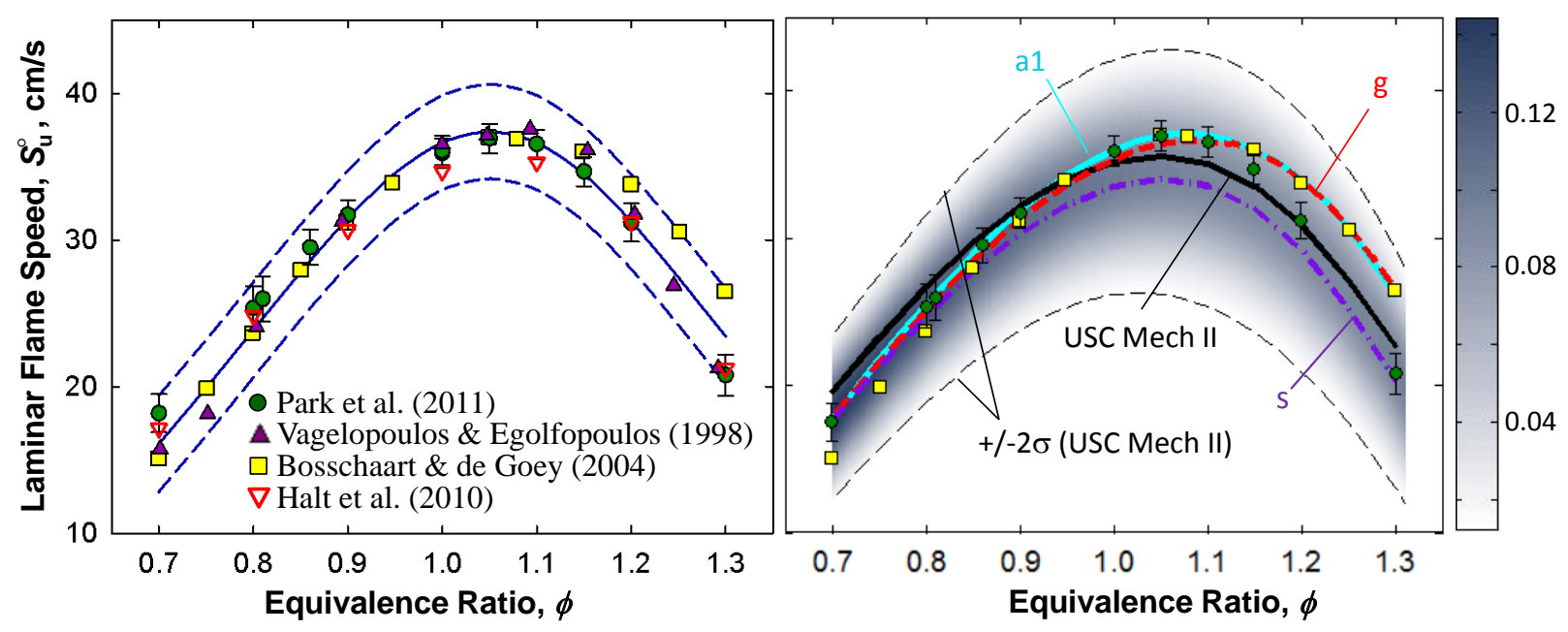

Figure 3. Left panel: selected experimental data (symbols) and results of uncertainty analysis (solid lines, nominal fits to data; dashed lines: $2 \sigma$ uncertainty) of $S_{u}^{\circ}$ of $\mathrm{CH}_{4} /$ air mixtures at $p=1$ atm and $T_{\mathrm{u}}=298 \mathrm{~K}$. Right panel: Selected experimental (symbols) and computed (lines) $S_{u}^{\circ}$ also at $p=1$ atm and $T_{\mathrm{u}}=298 \mathrm{~K}$. The error bars represent $2 \sigma$ uncertainty of the data. The grey level indicates the normalized probability density function of $S_{u}^{\circ}$ predicted by USC Mech II. See Table 1 for the labels of the models used for predictions. Symbols: $\bigcirc$ Park et al., 2011 [25]; $\triangle$ Vagelopoulos \& Egolfopoulos, 1998 [26]; Bosschaart \& de Goey, 2004 [27]; $\nabla$ Halt et al., 2010 [28]. 

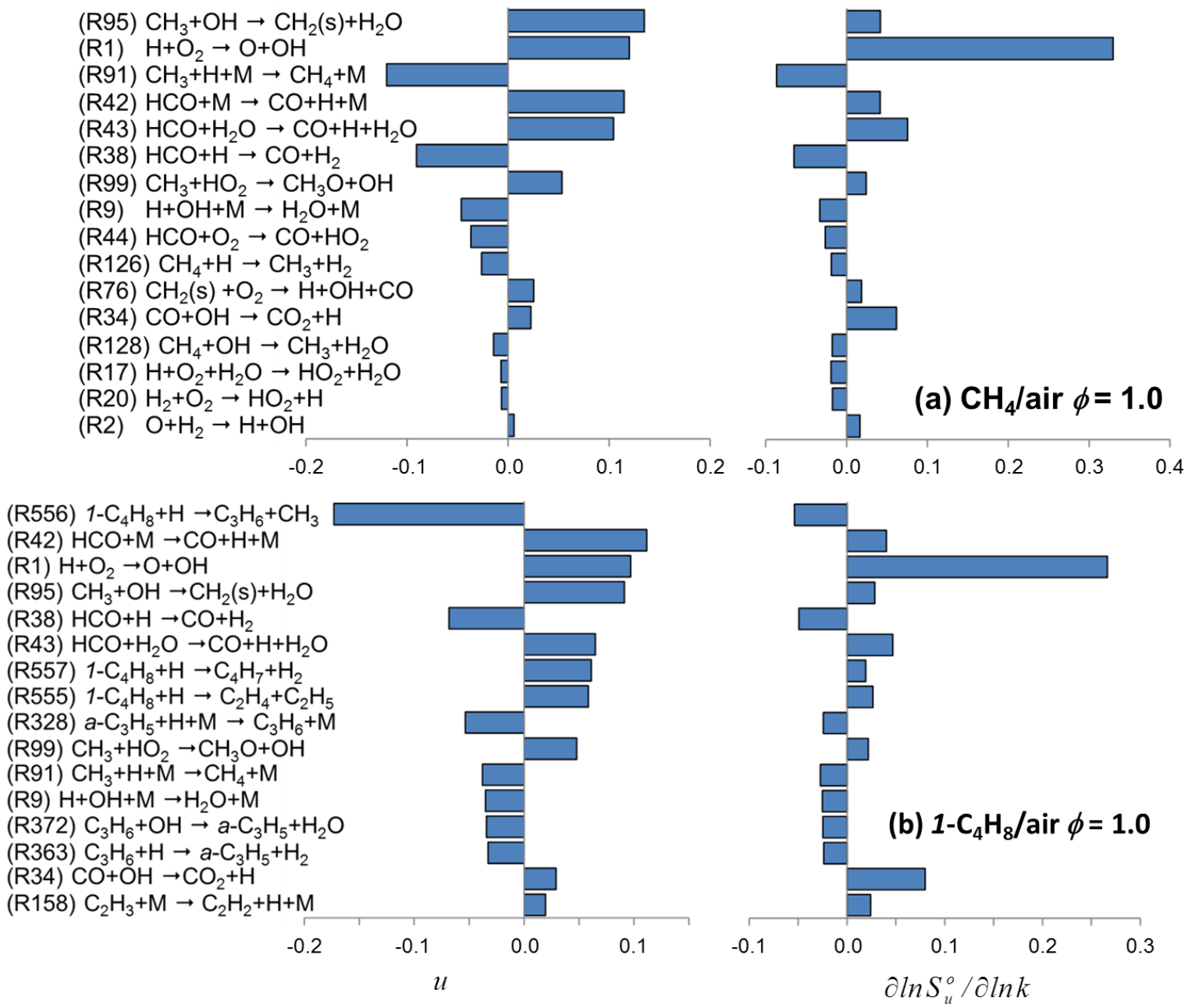

Figure 4. The ranked impact factor $u$ and logarithmic sensitivity coefficient $\partial \ln S_{u}^{\circ} / \partial \ln k$ computed for stoichiometric (a) $\mathrm{CH}_{4} /$ air and (b) $1-\mathrm{C}_{4} \mathrm{H}_{8} /$ air flames at $\phi=1.0, T_{u}=298 \mathrm{~K}$, and $p=1 \mathrm{~atm}$ using USC Mech II. 

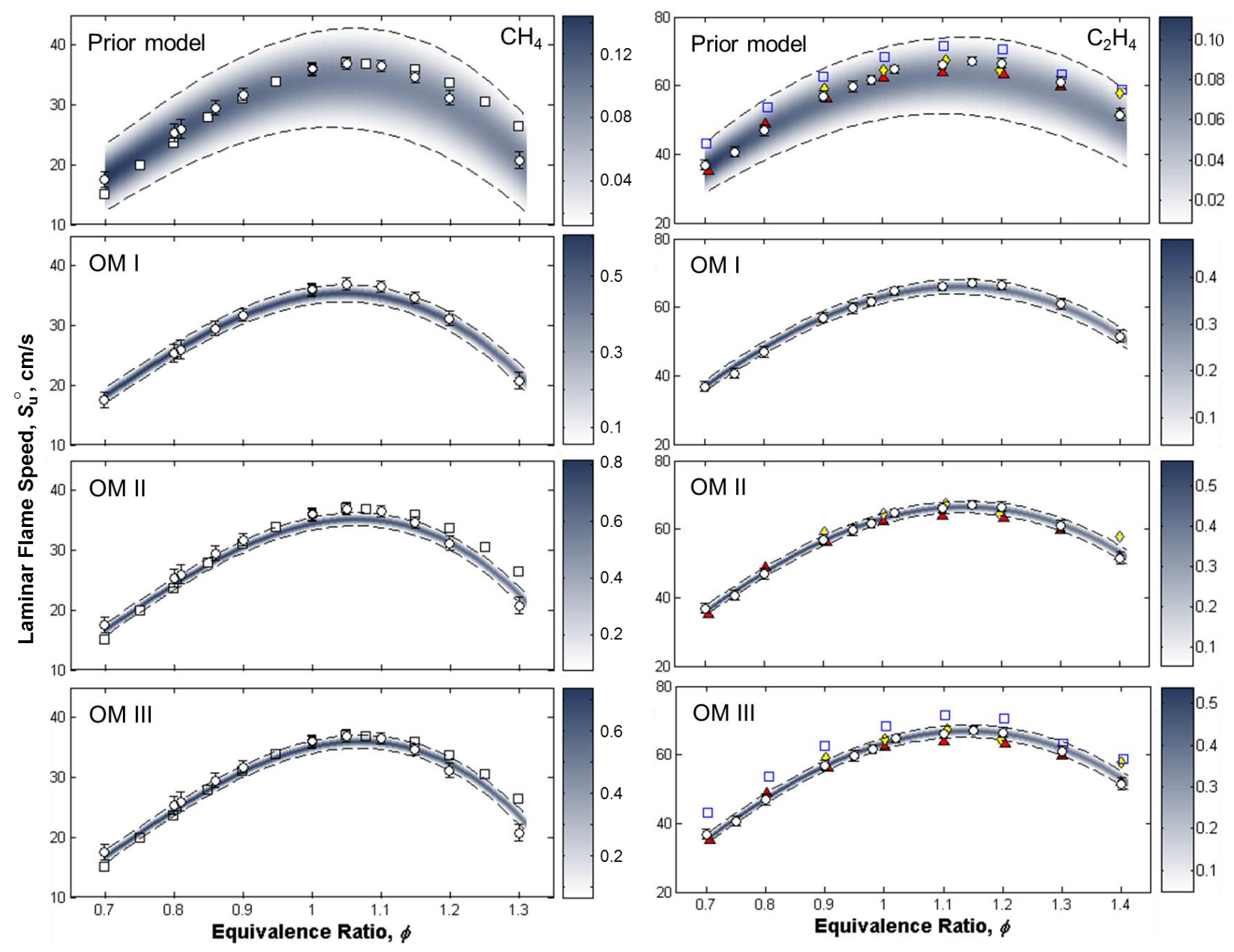

Figure 5. Experimental $(\bigcirc[24,25], \square[27], \triangle[4], \diamond[29])$ and computed (lines) $S_{u}^{\circ}$ of $\mathrm{CH}_{4} /$ air (left panel) and $\mathrm{C}_{2} \mathrm{H}_{4} /$ air (right panel) at $p=1 \mathrm{~atm}$ and $T_{\mathrm{u}}=298 \mathrm{~K}$ as a function of $\phi$. The grey level indicates the probability density function of the uncertainty of flame speed predicted by the prior and optimized models; the dashed lines correspond to $\pm 2 \sigma$ uncertainty of the respective models. 

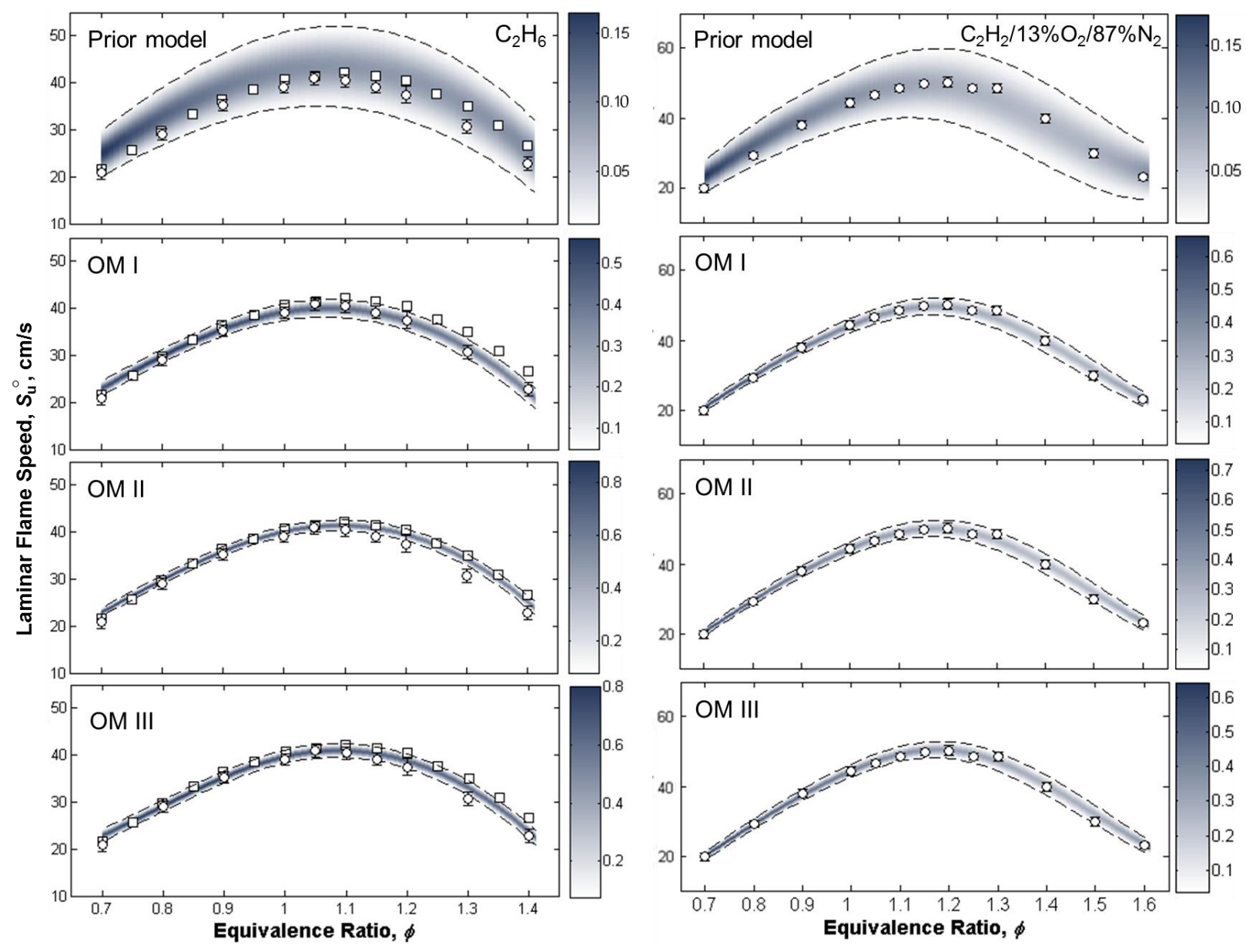

Figure 6. Experimental $\left(\bigcirc\right.$ [24], $\square$ [27]) and computed (lines) $S_{u}^{\circ}$ of ethane in air (left panel) and $\mathrm{C}_{2} \mathrm{H}_{2} / \mathrm{O}_{2} / \mathrm{N}_{2}$ mixtures (right panel) at $p=1$ atm and $T_{\mathrm{u}}=298 \mathrm{~K}$ as a function $\phi$. The grey level indicates the probability density function of the uncertainty of flame speed predicted by the prior and optimized models; the dashed lines correspond to $\pm 2 \sigma$ uncertainty of the respective models. 

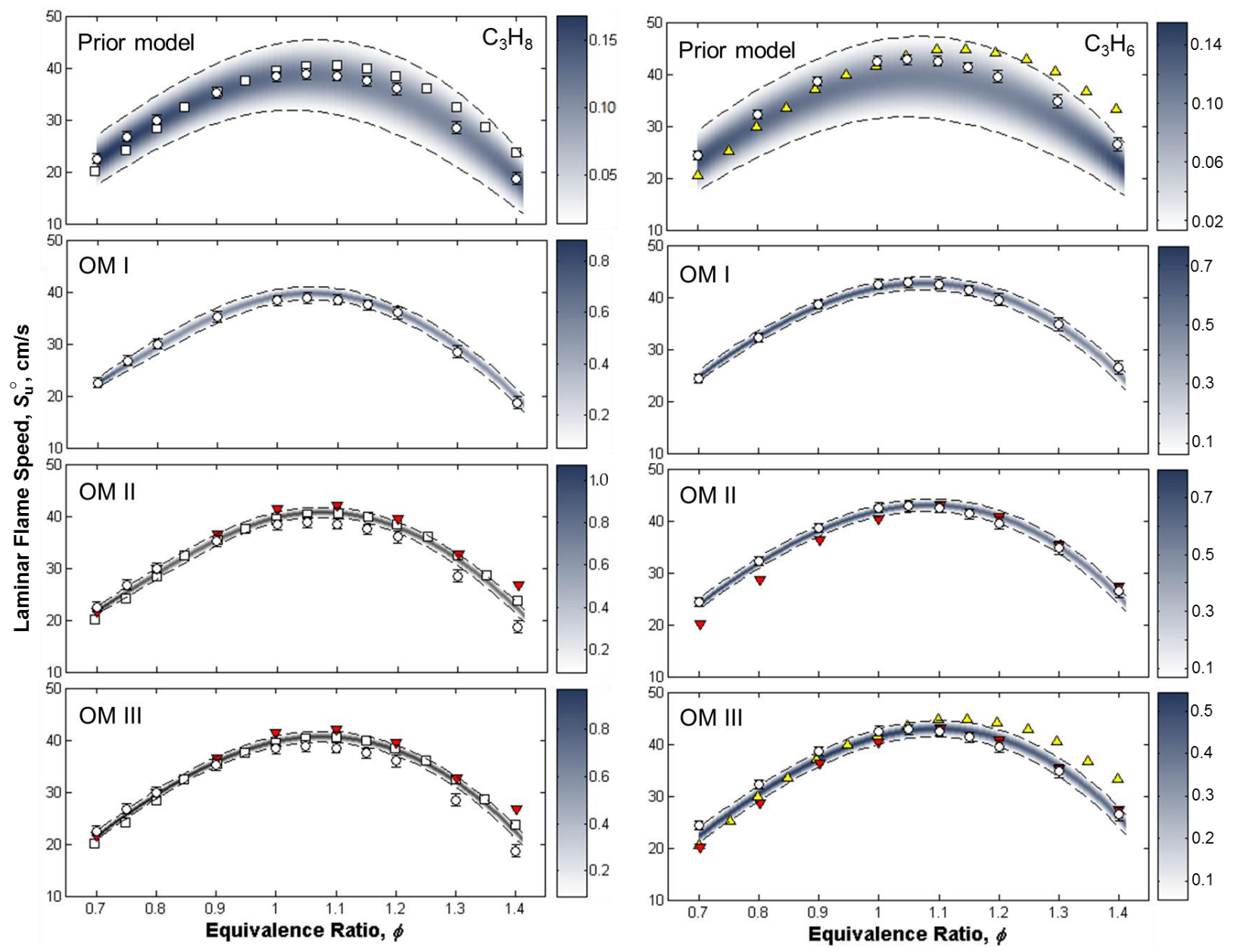

Figure 7. Experimental ( $\bigcirc$ this work, $\square$ [27], $\nabla$ [4], $\triangle$ [3]) and computed (lines) $S_{u}^{\circ}$ of $\mathrm{C}_{3} \mathrm{H}_{8} /$ air (left panel) and $\mathrm{C}_{3} \mathrm{H}_{6} /$ air (right panel) at $p=1 \mathrm{~atm}$ and $T_{\mathrm{u}}=298 \mathrm{~K}$ as a function of $\phi$. The grey level indicates the probability density function of the uncertainty of flame speed predicted by the prior and optimized models; the dashed lines correspond to $\pm 2 \sigma$ uncertainty of the respective models. 

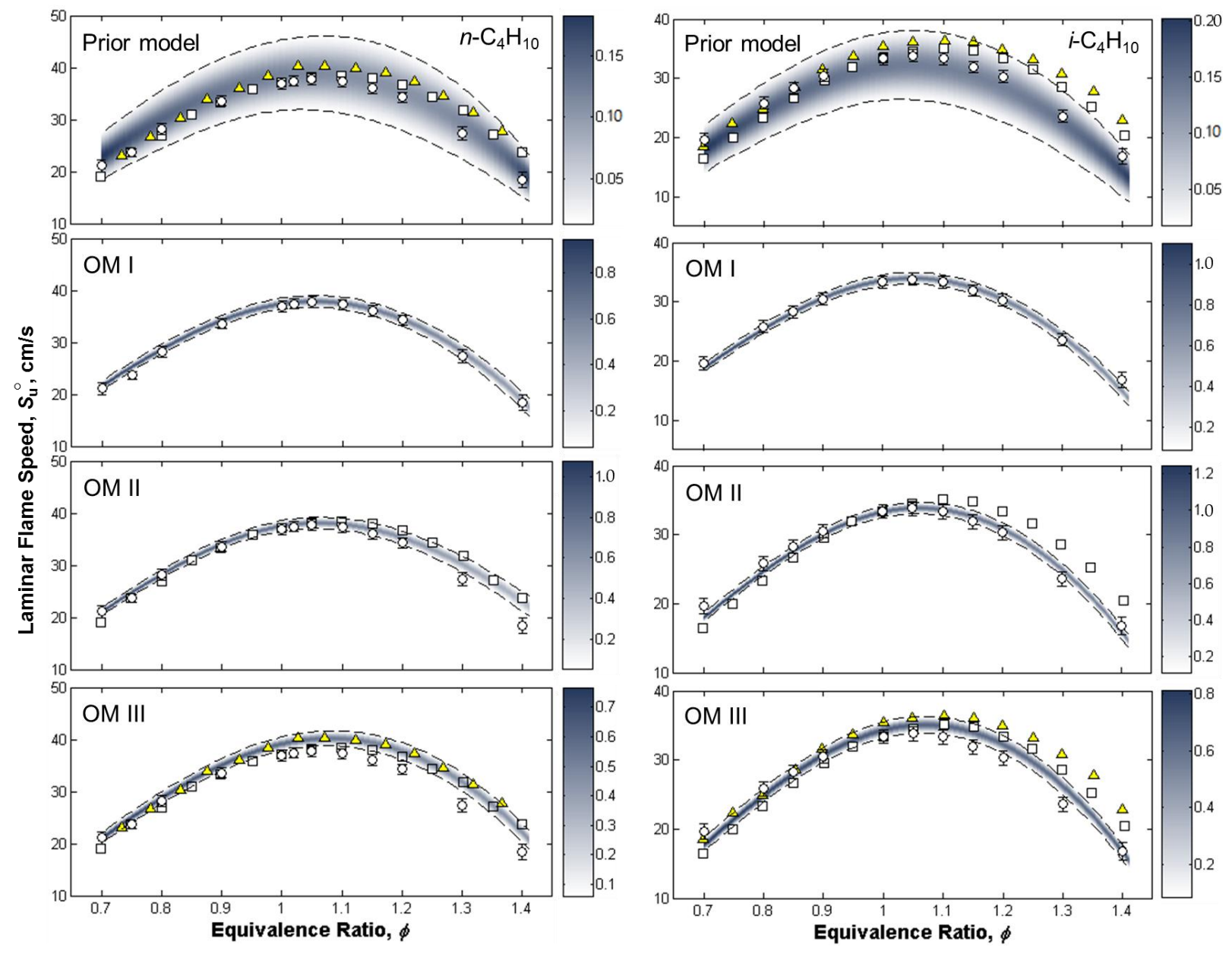

Figure 8. Experimental ( $\bigcirc$ this work, $\square$ [27], $\triangle[3]$ ) and computed (lines) $S_{u}^{\circ}$ of $n-\mathrm{C}_{4} \mathrm{H}_{10} /$ air (left panel) and $i-\mathrm{C}_{4} \mathrm{H}_{10} /$ air (right panel) at $p=1 \mathrm{~atm}$ and $T_{\mathrm{u}}=298 \mathrm{~K}$ as a function of $\phi$. The grey level indicates the probability density function of the uncertainty of flame speed predicted by the prior and optimized models; the dashed lines correspond to $\pm 2 \sigma$ uncertainty of the respective models. 

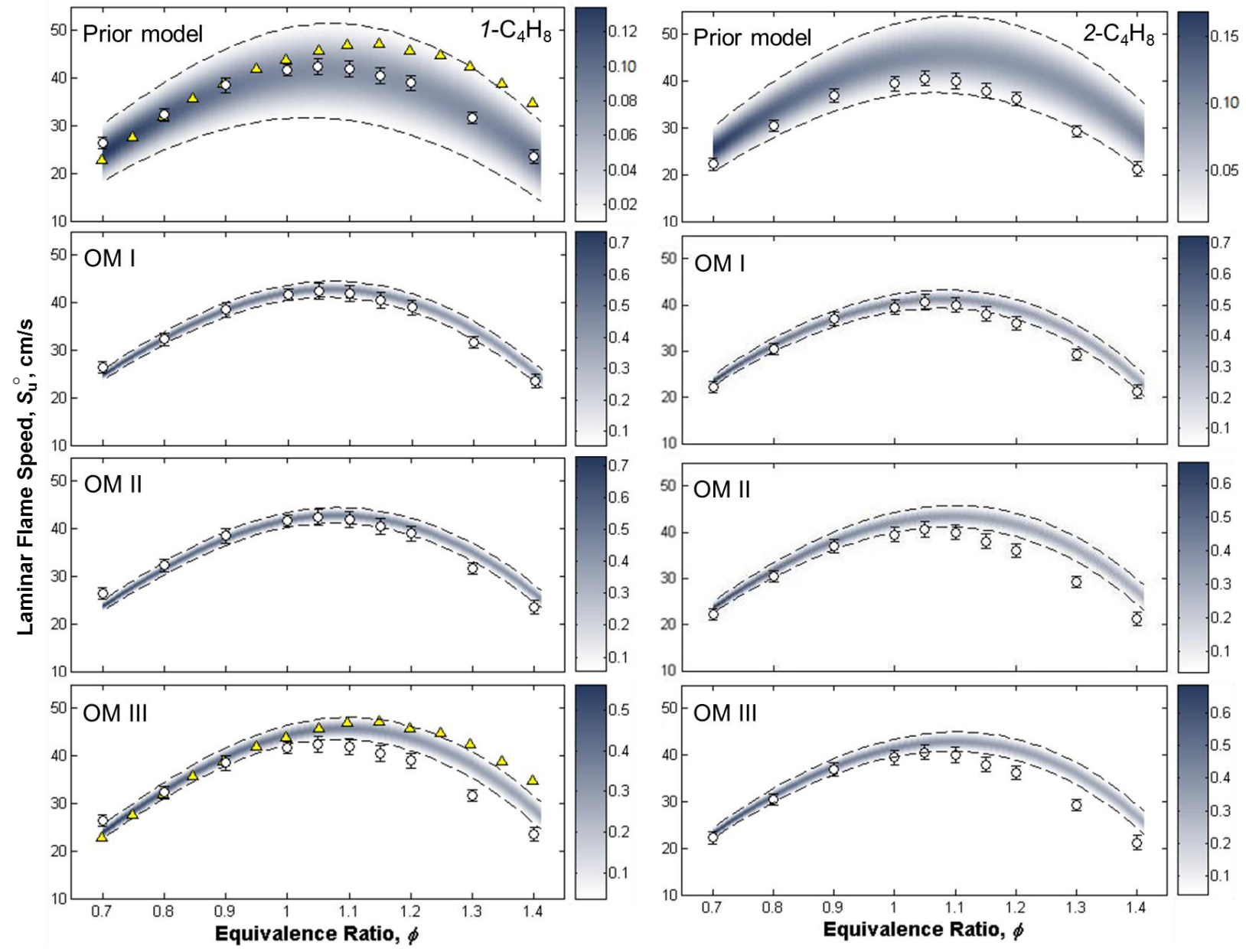

Figure 9. Experimental ( $\bigcirc$ this work; $\triangle[3]$ ) and computed (lines) $S_{u}^{\circ}$ of $1-\mathrm{C}_{4} \mathrm{H}_{8} /$ air (left panel) and 2$\mathrm{C}_{4} \mathrm{H}_{8} /$ air (right panel) at $p=1 \mathrm{~atm}$ and $T_{\mathrm{u}}=298 \mathrm{~K}$ as a function of $\phi$. The grey level indicates the probability density function of the uncertainty of flame speed predicted by the prior and optimized models; the dashed lines correspond to $\pm 2 \sigma$ uncertainty of the respective models. 

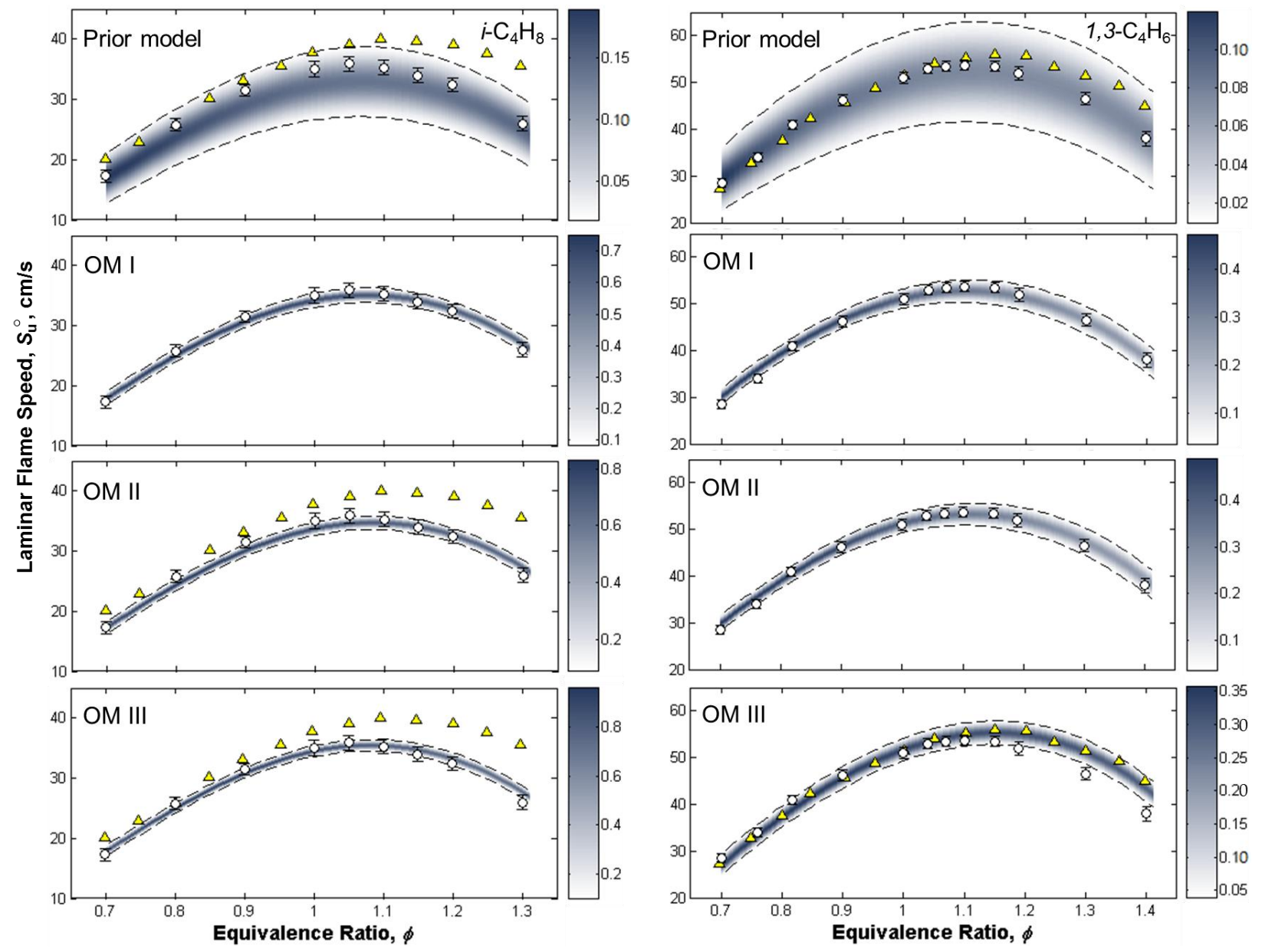

Figure 10. Experimental ( $\bigcirc$ this work; $\triangle[3]$ ) and computed (lines) $S_{u}^{\circ}$ of $i-\mathrm{C}_{4} \mathrm{H}_{8} /$ air (left panel) and $1,3-\mathrm{C}_{4} \mathrm{H}_{6} /$ air (right panel) at $p=1 \mathrm{~atm}$ and $T_{\mathrm{u}}=298 \mathrm{~K}$ as a function of $\phi$. The grey level indicates the probability density function of the uncertainty of flame speed predicted by the prior and optimized models; the dashed lines correspond to $\pm 2 \sigma$ uncertainty of the respective models. 

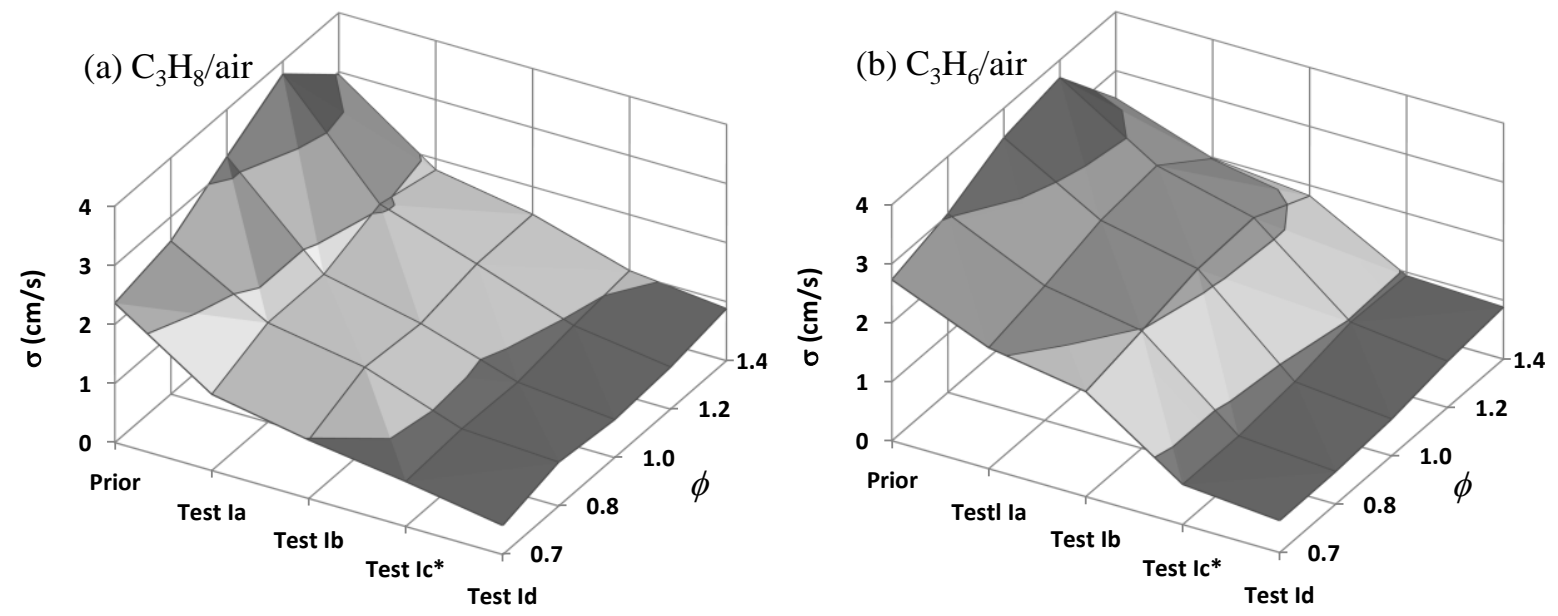

Figure 11. $1 \sigma$ uncertainty predicted for $S_{u}^{\circ}$ 's of (a) $\mathrm{C}_{3} \mathrm{H}_{8} /$ air and (b) $\mathrm{C}_{3} \mathrm{H}_{6} /$ air mixtures at $T_{\mathrm{u}}=298 \mathrm{~K}$ and $p=1 \mathrm{~atm}$. 

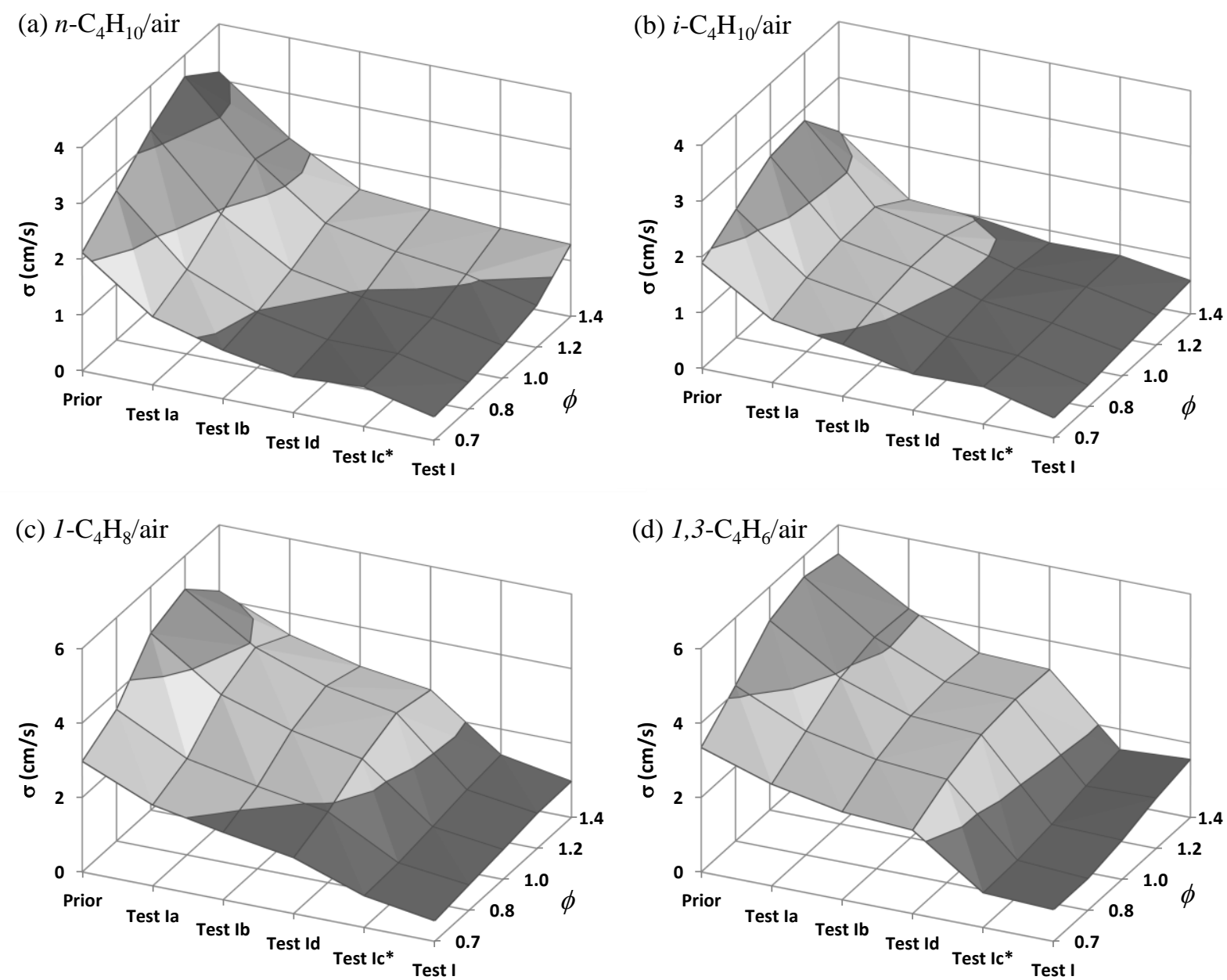

Figure 12. $1 \sigma$ uncertainty predicted for $S_{u}^{\circ}$ 's of (a) $n-\mathrm{C}_{4} \mathrm{H}_{10} /$ air, (b) $i-\mathrm{C}_{4} \mathrm{H}_{10}$ /air, (c) $1-\mathrm{C}_{4} \mathrm{H}_{8} /$ air, and (d) $1,3-\mathrm{C}_{4} \mathrm{H}_{6} /$ air mixtures at $T_{\mathrm{u}}=298 \mathrm{~K}$ and $p=1 \mathrm{~atm}$. 

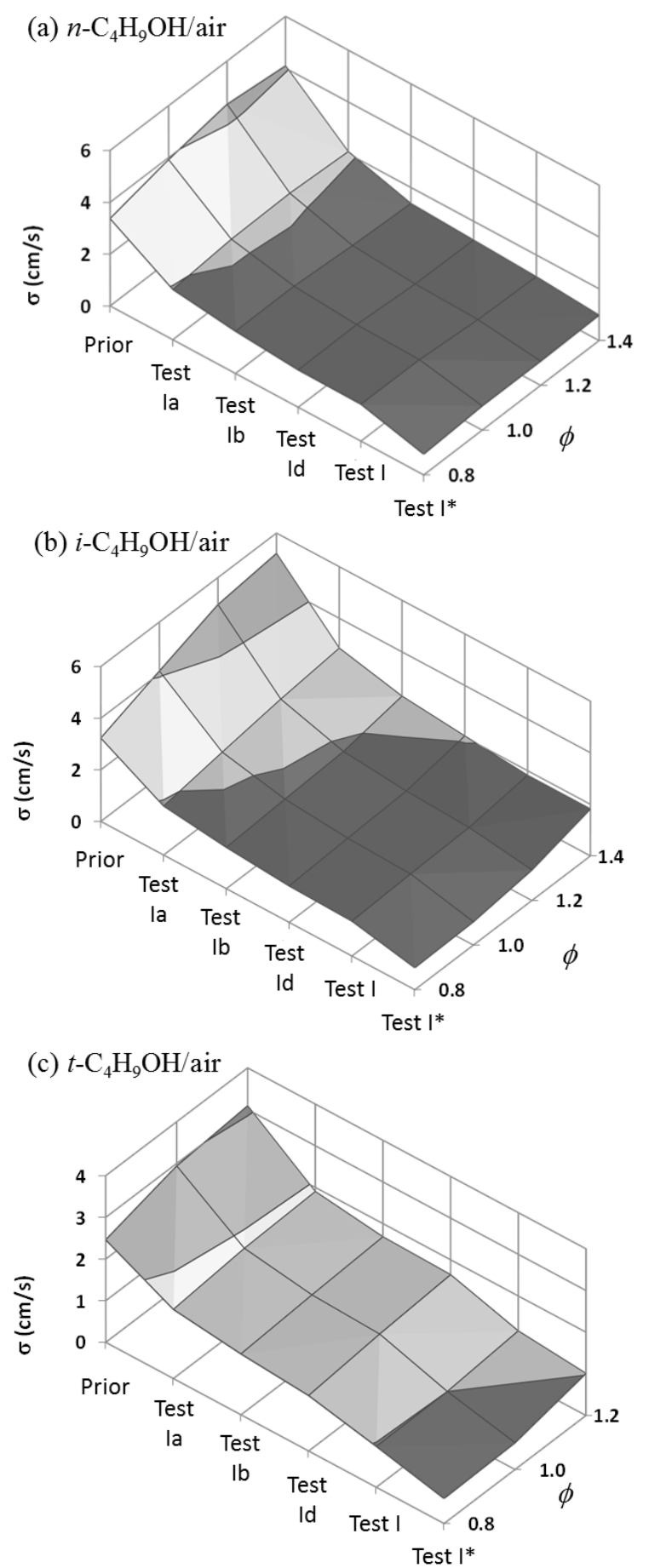

Figure 13. $1 \sigma$ uncertainty predicted for $S_{u}^{\circ}$ of (a) $n-\mathrm{C}_{4} \mathrm{H}_{9} \mathrm{OH} /$ air, (b) $i-\mathrm{C}_{4} \mathrm{H}_{9} \mathrm{OH} /$ air, and (c) $t-\mathrm{C}_{4} \mathrm{H}_{9} \mathrm{OH}$ mixtures at $T_{\mathrm{u}}=298 \mathrm{~K}$ and $p=1 \mathrm{~atm}$. 

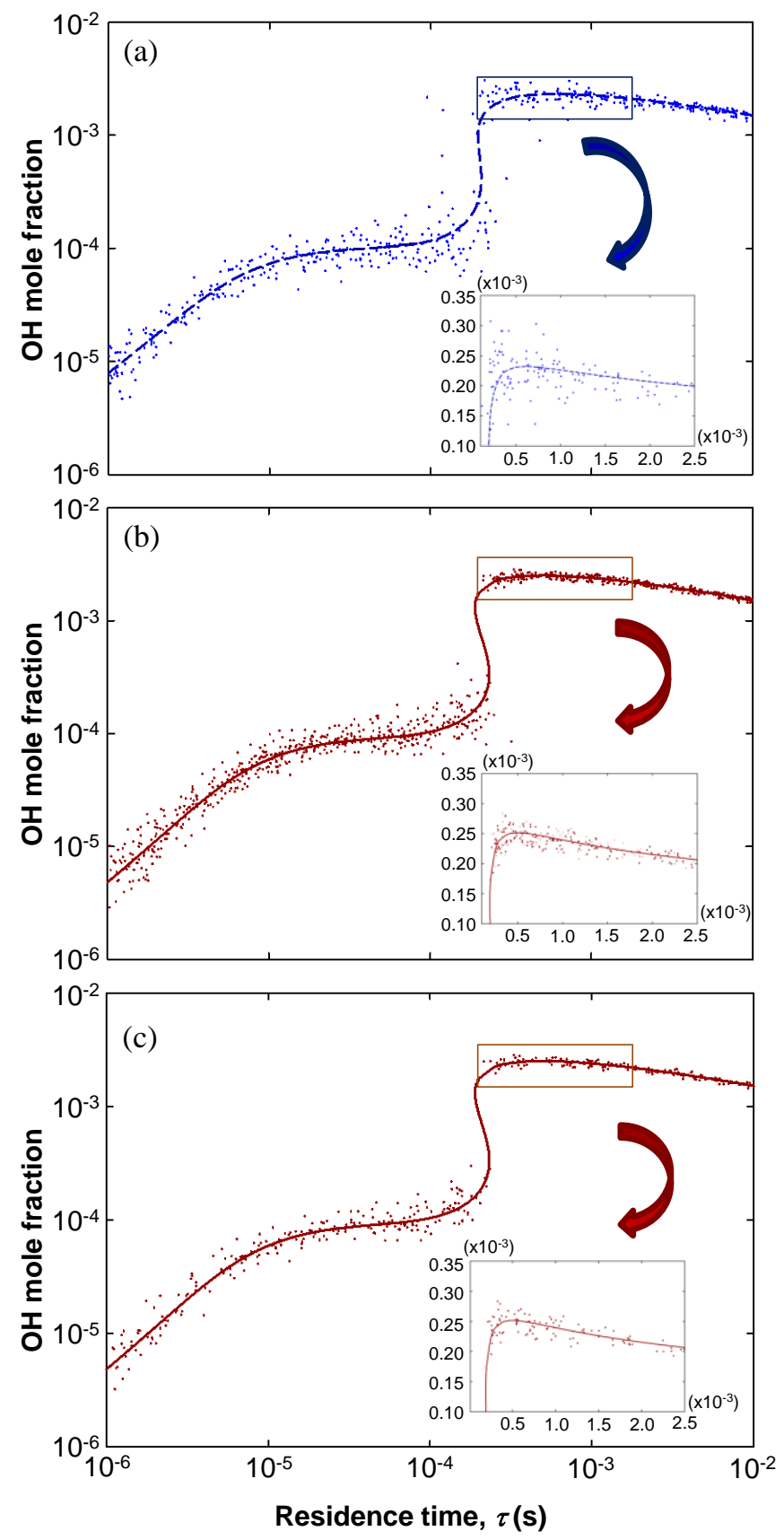

Figure 14. Variations of $\mathrm{OH}$ mole fraction with mean residence time in a simulated PSR in which $n$ $\mathrm{C}_{4} \mathrm{H}_{9} \mathrm{OH}$ is oxidized in stoichiometric air at a constant temperature of $1500 \mathrm{~K}$ and $1 \mathrm{~atm}$ pressure. (a) The prior model; (b) OM II; (c) OM II*. Lines are results of nominal predictions, and symbols are Monte Carlo sampling of the respective uncertainty spaces. 